\title{
Clinical management of tuberculosis and HIV-1 co-infection
}

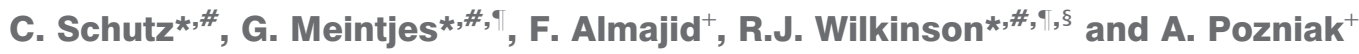

ABSTRACT: In many parts of the world the commonest serious opportunistic infection that occurs in HIV-1 infected persons is tuberculosis (TB). HIV-1 co-infection modifies the natural history and clinical presentation, and adversely affects the outcome of TB. Severe disseminated disease is well-recognised but it is increasingly appreciated that early disease characterised by very few or no symptoms is also common. Immunodiagnostic methods to ascertain latent TB in HIV-1 infected persons are compromised in sensitivity.

Chemoprevention of HIV-1-associated TB is effective, its benefits are restricted to those which have evidence of immune sensitisation and appear short-lived in areas of high TB burden. Although promising advances in the microbiological diagnosis of TB have recently occurred, the diagnosis of HIV-1-associated TB remains difficult because of more frequent presentation as sputum negative or extrapulmonary disease.

Management of co-infected patients can be complex because of overlapping drug toxicities and interactions. Nevertheless consensus is developing that antiretroviral therapy should be provided as soon as practicable after starting TB treatment in HIV-1 co-infected persons. This has the consequence of increasing the frequency of immune reconstitution inflammatory syndrome, the pathogenesis and management of which is poorly defined.

KEYWORDS: Complications, diagnosis, HIV-1, management, Mycobacterium tuberculosis

$\mathrm{n}$ the 30 yrs since the progressive immunosuppressive effects of HIV-1 were first recognised, tuberculosis (TB) has emerged as the most common serious opportunistic infection. This is especially the case in Sub-Saharan Africa where the advent of the HIV-1 pandemic has seriously derailed TB control. The remit of this article is to describe the modifying effect of HIV-1 infection on the clinical presentation and management of TB in HIV-1 infected persons.

\section{CLINICAL FEATURES OF HIV-1 ASSOCIATED TB}

Persons with HIV-1 infection are at increased risk of active TB due to reactivation of latent TB and more rapid progression to disease after $\mathrm{TB}$ infection. In TB endemic settings an annual risk of active TB of up to $30 \%$ in those with advanced HIV-1 has been documented [1]. The clinical presentation and course of active TB in HIV-1 infected persons are altered, particularly in those with advanced immunosuppression (CD4 counts $<200$ cells $\cdot \mathrm{mm}^{-3}$ ): active pulmonary TB can initially be asymptomatic; extrapulmonary TB is more common; the clinical course is accelerated; it is more difficult to diagnose; and mortality is higher.

In Europe and North America active TB predominantly occurs in HIV-1 infected patients with low CD4 counts $\left(<200\right.$ cells $\left.\cdot \mathrm{mm}^{-3}\right)$ [2] whereas in TB endemic settings, such as subSaharan Africa, it occurs across the spectrum of CD4 counts [3]. In a study conducted in the South African gold mines, the risk of TB doubled even in the first year after HIV-1 seroconversion [4]. The clinical presentation in HIV-1 infection is influenced by degree of immunodeficiency [5-7]. In patients with CD4 $>350$ cells $\cdot \mathrm{mm}^{-3}$, there are few differences in the clinical presentation compared with HIV-1 uninfected patients, whereas in

Previous articles in this series: No. 1: .Erkens CGM, Kamphorst M, Abubakar I, et al. Tuberculosis contact investigation in low prevalence countries: a European consensus. Eur Respir J 2010; 36: 925-949. No. 2: Solovic I, Sester M, Gomez-Reino JJ, et al. The risk of tuberculosis related to tumour necrosis factor antagonist therapies: a TBNET consensus statement. Eur Respir J 2010; 36: 1185-1206.

AFFILIATIONS

*Infectious Diseases Unit, GF Jooste Hospital, Manenberg, and \#Clinical Infectious Diseases Research Initiative, Institute of Infectious Diseases and Molecular Medicine and Dept of Medicine, Faculty of Health Sciences, University of Cape Town, Rondebosch, South Africa. 'Division of Medicine, Imperial College London, ${ }^{+}$Chelsea and Westminster Hospital NHS Trust, and

${ }^{\S}$ Medical Research Council National Institute for Medical Research, London, UK.

CORRESPONDENCE

C. Schutz

Infectious Diseases Unit

GF Jooste Hospital

Manenberg

7764

South Africa

E-mail: charlottelouw@

discoverymail.co.za

Received:

July 142010

Accepted after revision:

Oct 042010 
those with CD4 counts $<200$ cells $\cdot \mathrm{mm}^{-3}$ atypical clinical and radiographic features and more rapid progression are far more common [5, 6, 8, 9]. Multidrug-resistant (MDR)- and extensively drug-resistant (XDR)-TB are also emerging problems. MDR- and XDR-TB are associated with a high early mortality in the context of HIV-1 infection [10] and HIV-1 infection is an independent risk factor for death from drug-resistant TB [11].

\section{PRESENTATION OF PULMONARY TB}

Pulmonary TB remains the most frequent form of active TB in HIV-1 infected persons, even those with low CD4 counts. Although the clinical presentation of pulmonary TB is different to the presentation of pulmonary TB in HIV-1 uninfected patients, the most common symptoms remain cough, fever, night sweats and significant weight loss $[12,13]$. Relative to HIV-1 uninfected patients, weight loss and fever are more common, whereas haemoptysis is less common and some studies have reported a decreased proportion of patients with cough [14, 15]. The latter observations relate to a reduced inflammatory response resulting in less pulmonary cavitation and endobronchial involvement $[8,9]$.

Whereas many case detection algorithms for TB include cough of $\geqslant 2-3$ weeks duration in their criteria, it is important to note that cough of $<3$ weeks can be a presenting feature in HIV-1 infected patients. In Brazil, a third of patients with pulmonary TB were diagnosed when cough had been present for $\leqslant 3$ weeks [16]. In Malawi, amongst patients (53\% of whom were HIV-1 co-infected) with a cough of $<3$ weeks duration and no response to oral antibiotics, $35 \%$ were found to have pulmonary TB. [17]. In regions with a high incidence of $\mathrm{TB}$, persistent cough even for $<3$ weeks is suspicious for active TB in HIV-1-infected individuals.

Significant weight loss is observed in up to $85 \%$ of patients from Africa at the diagnosis of TB [8]. In a large study in Thailand looking at screening for TB in HIV-1 infected patients, weight loss occurred in $50 \%$ of patients who were screened and had a negative predictive value of 92\% [18] Weight loss was reported more frequently in patients with a $\mathrm{CD} 4<200$ cells $\cdot \mathrm{mm}^{-3}$ when compared to patients with higher CD4 counts in Brazil [16]. This has also been observed in Africa where weight loss $>10 \%$ was strongly correlated with a CD4 $<200$ cells $\cdot \mathrm{mm}^{-3}$ [3]. Weight loss was found to discriminate between pulmonary $\mathrm{TB}$ and other pulmonary infections (Pneumocystis jiroveci pneumonia and bacterial pneumonia) in HIV-1-infected patients (OR 3.6) in one study [14]. In the same study, fever for $>7$ days was also strongly associated with a TB diagnosis (OR 3.9) [14].

\section{ASYMPTOMATIC ACTIVE PULMONARY TB}

Prevalence surveys and intensified case finding studies that rely on sputum culture have brought to prominence the phenomenon of HIV-1 infected patients having sputum culture-positive TB in the absence of symptoms [19-21]. SWAMINATHAN et al. [20] described 10 such patients (CD4 count range 72-552). During an active case finding study in a high TB and HIV-1 prevalence community in South Africa, among 762 adults enrolled investigators found 12 cases of previously undiagnosed, sputum culture-positive TB, nine of whom were HIV-1 infected. Symptoms were not a useful screen for TB in these patients [21]. Four out of 14 Tanzanian HIV-1 infected patients with CD4 $\leqslant 200$ diagnosed with pulmonary TB (positive sputum microscopy or culture) during screening for a vaccine study were asymptomatic with a normal chest radiograph [19]. This phenomenon is one of the reasons why symptoms screens have reduced sensitivity in HIV-1 infected patients [19-21]. In South Africa one or more of cough for $\geqslant 2$ weeks, night sweats, fever or significant recent weight loss were reported in only $79 \%$ of patients diagnosed with TB on the basis of a positive sputum culture. Importantly, $62 \%$ of patients without TB had one or more of these symptoms, suggesting suboptimal sensitivity and specificity of this symptom screen [22]. In contrast, a recent study in South East Asia found that a screening tool requiring any one of three symptoms (cough of any duration, fever of any duration and night sweats for $\geqslant 3$ weeks duration in the preceding 4 weeks) performed well with a sensitivity of $93 \%$ among 1,748 HIV-1 infected patients, $15 \%$ of whom had culture proven TB. The study included extrapulmonary TB cases [18]. This suggests screening for TB in HIV-1 infected persons in the setting of a high TB burden, the best approach is to use symptom screen in conjunction with induced sputum culture. However, this poses significant programmatic challenges and laboratory cross contamination is also a problem in areas of high TB incidence [23, 24]. Symptom screen could be repeated at each follow-up visit.

\section{EXTRAPULMONARY TB}

Extrapulmonary TB and disseminated TB (active TB at more than one non-contiguous anatomical location) are more common in HIV-1 infected persons, especially as the CD4 count declines [25-28]. Wide dissemination of TB in advanced HIV-1 may occur [29]. There may or may not be coexistent pulmonary TB. In Zambia, amongst HIV-1 uninfected TB patients, $72 \%$ had pulmonary TB alone, $16 \%$ extrapulmonary TB alone and $12 \%$ had both. Among HIV-1 infected patients, $40 \%$ had pulmonary disease alone, 34\% extrapulmonary disease alone and $26 \%$ both [30]. More striking differences between HIV-1 uninfected and infected patients have been reported in a review combining data from several studies: pulmonary TB alone was present in $80 \%$ versus $30 \%$, extrapulmonary TB alone in $15 \%$ versus $20 \%$ and both in $5 \%$ versus $50 \%$ [31]. In the USA, HIV-1 infected TB patients with CD4 $>300$ had overt evidence of extrapulmonary involvement in $28 \%$ of cases, $44 \%$ in those with a CD 4 count $201-300,50 \%$ in those with a CD4 count 101-200 and 70\% in those with a CD4 count $\leqslant 100$ [7].

The most frequent extrapulmonary sites in HIV-1 infected and uninfected persons have been reported to be lymphadenitis $(35 \%)$ and pleural effusion (20\%) [31], other sites include other serosal surfaces (pericardial and peritoneal), abdominal (involving liver, spleen, peritoneal surface and/or lymph nodes) and neurological $[8,32]$. Splenic hypodensities reflecting multiple microabscesses and abdominal lymphadenopathy are common ultrasound findings in HIV-1-infected patients with disseminated TB [33]. Mycobacteraemia is more common in HIV-1 [20, 34]. In South Africa, $28 \%$ of HIV-1 infected patients with smear-negative TB had positive mycobacterial blood cultures [35]. Mycobacteraemia has been reported to be more common as the CD4 count declines and in patients with CD4 $\leqslant 100$ mycobacteraemia has been reported in up to $49 \%$ [7]. Patients with advanced HIV-1 and mycobacteraemia may present with 
sepsis syndrome and septic shock [36, 37]. Severe wasting illness with or without associated diarrhoea may be the only clinical feature of disseminated TB in HIV-1 [6, 29]; although, in such patients it is important to investigate for other HIV-1 related opportunistic infections that may account for over half of such presentations rather than TB (table 1) [38].

Like HIV-1 uninfected patients, HIV-1 infected patients can present with a range of neurological manifestations: tuberculous meningitis (TBM), tuberculomas, radiculomyelitis and tuberculous brain abscess [39]. In patients with TB, meningeal involvement is more common in HIV-1-infected patients [40, 41]. One study of $3,710 \mathrm{~TB}$ cases demonstrated meningeal involvement in $6.4 \%$ of HIV-1-infected patients compared to $1.2 \%$ of HIV-1-uninfected patients [41]. TBM generally presents with similar clinical and cerebrospinal fluid (CSF) findings in the HIV-1-infected compared to the HIV-1-uninfected patients [42]. Acellular and completely normal CSF examinations have, however, been described in HIV-1-infected patients with TBM [40, 43, 44]. HIV-1-infected TBM patients more frequently also have extra-meningeal TB [41, 42, 44].

While most extrapulmonary manifestations are more common in HIV-1, extraspinal tuberculous arthritis appears to occur less frequently [45]. Clinical features of disseminated TB depend upon anatomical location $[32,46]$ and systemic symptoms can be nonspecific. Given that $40-60 \%$ of cases of disseminated TB have co-existent pulmonary TB [8], patients presenting with features of disseminated TB should always have sputum sent for TB microscopy and culture. HIV-1 may modulate the complications of extrapulmonary TB. For example, HIV-1 infected patients are reported to be less prone to developing constriction as a complication of pericardial TB [47].

TABLE 1 Disorders that occur commonly in HIV-1 infected
patients and should be considered in the
differential diagnoses for tuberculosis (TB)

\section{RAPID PROGRESSION AND HIGHER MORTALITY}

TB tends to progress more rapidly in HIV-1 infected persons and may present as an acute illness [6, 48]. Amongst SouthAfrican gold miners who were diagnosed with TB the mean duration of smear positivity before diagnosis was substantially shorter for HIV-1-infected compared to uninfected TB patients (0.17 and 1.15 yrs, respectively) [48]. This indicates more rapid progression of disease and subsequent diagnosis of $\mathrm{TB}$ in HIV-1 infected patients compared to TB patients who were not HIV-1 infected. Similar findings were noted in a communitybased study in Zimbabwe: duration of infectiousness prior to TB diagnosis was 18 weeks for HIV-1 infected versus 1 yr for HIV-1 uninfected patients [49]. TB may also present as an acute community acquired pneumonia and needs to be considered in any HIV-1 infected patient presenting with acute respiratory illness (table 1) [50, 51].

Several studies from sub-Saharan Africa have demonstrated that TB is present in approximately half of HIV-1 infected persons at post mortem and in many TB was not diagnosed ante mortem. Therefore, it is critical to investigate, diagnose and start TB treatment rapidly in HIV-1 infected patients, to reduce morbidity, the need for hospitalisation and mortality which may result from rapid deterioration $[29,52]$. The rapidity of deterioration in HIV-1 patients with TB, as well as difficulties in diagnosis (discussed below), contributes to this. During treatment, mortality is higher for HIV-1 infected patients [5355] due to both advanced TB disease at diagnosis and other opportunistic infections. Amongst South African gold miners 6-month mortality in HIV-1 infected patients with TB was 13\% compared to $0.5 \%$ in HIV-1 uninfected patients [53]. In Brazil the mortality rate in HIV-1 infected TB patients was 24.7 per 100 patient yrs compared to 2.5 per 100 patient yrs amongst HIV-1 uninfected patients. Although mortality was substantially reduced amongst patients on antiretroviral therapy (ART), it was still significantly higher than HIV-1 uninfected TB patients (HR 6.6) [54].

\section{DIAGNOSIS OF TB IN HIV-1 INFECTED PERSONS Latent TB in HIV-1 infected persons}

Latent TB is inferred solely by evidence of immunological sensitisation to mycobacterial proteins by a positive tuberculin skin test (TST) or a positive interferon-gamma release assay (IGRA) in the absence of symptoms or signs of active disease $[56,57]$. The evidence for latency arises from historical studies in which Mycobacterium tuberculosis was isolated post mortem from lesions in otherwise disease-free persons [56]. From TST surveys it is inferred that one third of the world's population has latent TB infection. This presents an enormous reservoir of infected persons who could potentially develop active disease. However, several features of the epidemiology of HIV-1associated TB require modification of the concept of latency [58]. First, HIV-1 infected persons more often and rapidly progress to disease following infection than the often-quoted $5-10 \%$ life-time risk $[4,59-61]$. The annual risk of active TB is up to $30 \%$ in HIV-1 infected individuals [1]. Secondly, in cases of recurrent $\mathrm{TB}$, it has become clear that this often represents re-infection rather than endogenous reactivation: this is particularly the case in high-incidence environments [62, 63]. Thirdly, the existence of a substantial prevalence of asymptomatic early HIV-1-associated TB, as outlined above, indicates 
that bacterial replication is a feature of minimally symptomatic disease [21, 48, 49,59]. Indeed this has always been inferred because the most tested treatment for latent infection, isoniazid (INH), kills replicating bacilli.

\section{DIAGNOSIS OF LATENT TB IN HIV-1 INFECTED PERSONS}

Despite flaws, the TST remains the best-validated method of inferring latent TB infection, and predicting risk of progression and benefit from INH preventive therapy (IPT). The flaws of the TST have been extensively discussed: false positives occur because the purified protein derivative reagent contains many antigens present in bacille Calmette-Guérin (BCG) and nonpathogenic mycobacteria, and false negatives occur in the immunocompromised, early in primary $\mathrm{TB}$ and in disseminated TB [64]. The test cannot distinguish active infection from latent infection. Administration and reading require two clinic visits and occasionally the reaction may scar.

Early studies established that in HIV-1 infected persons the sensitivity of the TST is markedly diminished especially as the CD4 count declines [65-67]. In a comparison of similar HIV-1 infected and uninfected persons in a high-incidence area of South Africa, $52 \%$ of HIV-1 infected persons had a reaction $>5 \mathrm{~mm}$, whereas $86 \%$ of those uninfected had reactions $>5 \mathrm{~mm}$. The corresponding figures for the $10 \mathrm{~mm}$ cut-off were $49 \%$ and $83 \%$, respectively [68].

In recognition of these deficiencies of the TST, in the last 10 yrs in vitro IGRAs have been developed and commercialised as a potential replacement. IGRAs depend on in vitro restimulation of lymphocytes by antigens that are either deleted from the genome of all BCG strains (early secreted antigenic target $6 \mathrm{KDa}$ protein and culture filtrate protein-10 [69, 70]) or encoded on an evolutionarily recent prophage insertion into the genome of modern pathogenic $M$. tuberculosis strains (TB7.7 encoded by Rv2654c [71]). Although a laboratory capable of cell culture and ELISA is required, IGRA tests have operational advantages over the TST as they require a single patient visit and render a quantitative result that may remain relevant for some time whereas a missed TST reading means the test can only be repeated. IGRA have relatively low inter-observer variability and, providing no TST is simultaneously administered [72], repeat testing does not boost the response. There is consensus that IGRA are of higher specificity for diagnosing TB infection in BCG vaccinated persons [73]. Like the TST, they have limited ability to differentiate between active disease and latent infection.

The potential advantages of IGRA testing have encouraged evaluation of these tests in HIV-1 infected persons with three aims being pertinent. First, is the sensitivity of IGRA to detect TB infection in HIV-1 infection less impaired than the TST? Secondly, do IGRA tests better predict subsequent active TB and thus better guide the prescribing of preventive therapy? Thirdly, can IGRA tests aide the diagnosis of active HIV-1 associated TB? With respect to latent TB these aims are, however, confounded by the following factors. First, there is no 'gold-standard' for latent TB and so studies have tended to use the sensitivity to detect active culture proven TB (see below) as a proxy. This is likely to lead to an overestimate of sensitivity because it is recognised experimentally and in humans that there is a relationship between bacillary counts and the peripheral response to ESAT-6 and CFP-10 proteins [74-78] As HIV-1 infected persons with latent TB presumably have relatively low bacillary counts and an impaired immune response it follows that a lower frequency of positive results would be expected in the profoundly immunosuppressed. A second factor must also be considered when interpreting variable findings on this subject. Whilst the term IGRA is catchy, it implies that tests are generic and interchangeable which they are not. Importantly, the laboratory base for the ELISpot based T-Spot.TB test is a fixed number of peripheral blood mononuclear cells whereas the QuantiFERON tests use whole blood. As numbers of CD4+ T-cells decline, isolation of peripheral blood mononuclear cell might tend to partially offset that decrease whereas the absolute numbers of CD4 cells (upon which both tests rely) will obviously decrease in whole blood $[79,80]$.

Only a minority of studies of IGRA have included HIV-1 infected persons who may have latent TB. Study design is markedly heterogeneous and very few studies have encompassed latent infection in a high incidence environment. The TSpot.TB test has less frequently been studied than the QuantiFERON tests. However, several conclusions can be made from existing studies. First, it is commonly observed that the rate of indeterminate assays (due a negative response in the positive control well or tube) increases as the CD4 count declines [81-86]. In the few studies in which 'head to head' three-way comparisons have been made, data are conflicting as to whether this effect is greater with QuantiFERON tests $[68,85]$ or for the T-Spot.TB $[86,87]$. It is certainly the case that the TSpot.TB test requires greater laboratory sophistication. Almost all studies of HIV-1 infected persons report that agreement between the IGRAs and TST is sometimes poor and rarely better than fair with kappa values in the range 0.3-0.5 [68, 83-87]. This disconcordance might feasibly be of prognostic significance but it is very difficult to evaluate which is best at predicting subsequent TB. Only a single study has reported the predictive value of a baseline positive IGRA test for subsequent TB in HIV-1 infected persons. AichelBERG et al. [81] performed QuantiFERON Gold-in tube testing on $830 \mathrm{HIV}-1$ infected persons attending a clinic in Austria. 44 were found to be positive of whom seven had prevalent TB. Three of the remaining 37 (and none of those negative) developed bacteriologically unproven TB during follow-up. It is difficult to avoid the frequently made conclusion that further studies would be required, especially in high incidence environments, to determine whether these tests could become a routine part of care in HIV-1 infected persons without evidence of active TB.

\section{DIAGNOSIS OF ACTIVE TB}

TB diagnostics have benefited considerable innovation in the last $10-15$ yrs and there is now optimism that some new tests can be implemented that will hopefully translate into better health outcomes. An important distinction needs to be made between tests applicable at national and regional reference laboratories and those intended for point of care, which is the most demanding scenario. Benchmarking new techniques to diagnose active TB is guided by the diagnostic gold standard for active TB, which is microbiological isolation of M. tuberculosis. However, the detection of acid-fast bacilli by microscopy 
remains the only available laboratory test to diagnose active TB in most resource-limited settings. Sputum microscopy is inexpensive, of high specificity and detects the most infectious patients [88]. However, sputum microscopy is insensitive: a feature exacerbated by HIV-1 co-infection because the frequency of smear-negative and culture-positive cases is increased (fig. 1) $[64,88,103]$. Fluorescence microscopy appears more sensitive than conventional microscopy and has similar specificity [104], but has not been as widely studied in HIV-1-infected persons. The advent of light emitting diode fluorescent microscopes that appear to equal the performance of the more complex mercury vapour lamp based devices is also an advance [105]. Sputum induction has been referenced in medical research literature since the 1960s as an effective tool for the diagnosis of TB in patients who are smear-negative or unable to produce sputum [106]. Studies in HIV-1 infected persons are relatively few. HARTUNG et al. [107] demonstrated that sputum induction performed on smear-negative patients or those unable to expectorate increased their diagnosis of TB by $29 \%$. Similarly, PARRY et al. [108] observed a 19\% increase in TB diagnoses when sputum induction was evaluated in Malawi.

In the absence of a positive smear the chest radiograph may play an important role in the diagnosis of HIV-1 patients with suspected TB. There are several chest radiograph features that are highly suggestive of $\mathrm{TB}$, but none are diagnostic [17, 26, 38]. The degree of immunosuppression plays a critical role in the radiographic pattern $[8,9]$. Persons with relatively wellpreserved immunity (CD4 cell count $>200$ cells $\left.\mu \mathrm{L}^{-1}\right)$ can present with a typical adult pattern with upper lobe predominance and cavitation. In patients with more advanced immunosuppression (CD4 cell count $<200$ cells $\cdot \mu \mathrm{L}^{-1}$ ) the radiological features tend to be more atypical with mid- or lower-zone infiltrates and hilar and mediastinal lymphadenopathy $[8,9,16$, $27,109]$. Pleural effusions can occur irrespective of immune status [16]. A miliary pattern occurs commonly with more advanced immunosuppression [8]. It is also well described that HIV-1 infected patients with active TB proven on sputum culture can have normal chest radiographs $[16,19,26]$.

In the absence of any microbiological evidence of $\mathrm{TB}$, guidelines for diagnosis exist [110]. Expanded case definitions have performed well but should be combined with follow-up and objective assessment of response to treatment [38]. HIV-1 infected patients with smear-negative TB have a higher mortality than smear positive patients [9, 38, 111, 112]. Therefore, it is important that patients who fail to respond to treatment for smear-negative TB should be referred for further investigation as they may have drug-resistant disease or an alternative diagnosis (table 1) [38].

Culture of $M$. tuberculosis on solid media may be prolonged. Liquid culture media significantly reduces the time and effort of obtaining a positive culture [6, 26, 113] but is not infrequently associated with contamination (up to 17\%) [114]. It is also expensive to establish and thereby not routinely available in many resource-limited settings [64]. An alternative lower cost liquid-based culture technique is the microscopic observation drug sensitivity (MODS) assay in which tangles of mycobacteria are directly visualised via an inverted microscope [115]. An additional advantage is the ability to simultaneously determine drug resistance. Several subsequent evaluations of MODS have found it to be equivalent or slightly superior to automated liquid culture for the diagnosis of both pulmonary and extrapulmonary TB [116, 117]. However, no commercially available form of the test exists.

Present commercially available and several 'in house' nucleicacid amplification (NAAT) tests have a high specificity for $M$. tuberculosis, and high sensitivity in smear-positive sputum. However, sensitivity in smear-negative TB and disseminated

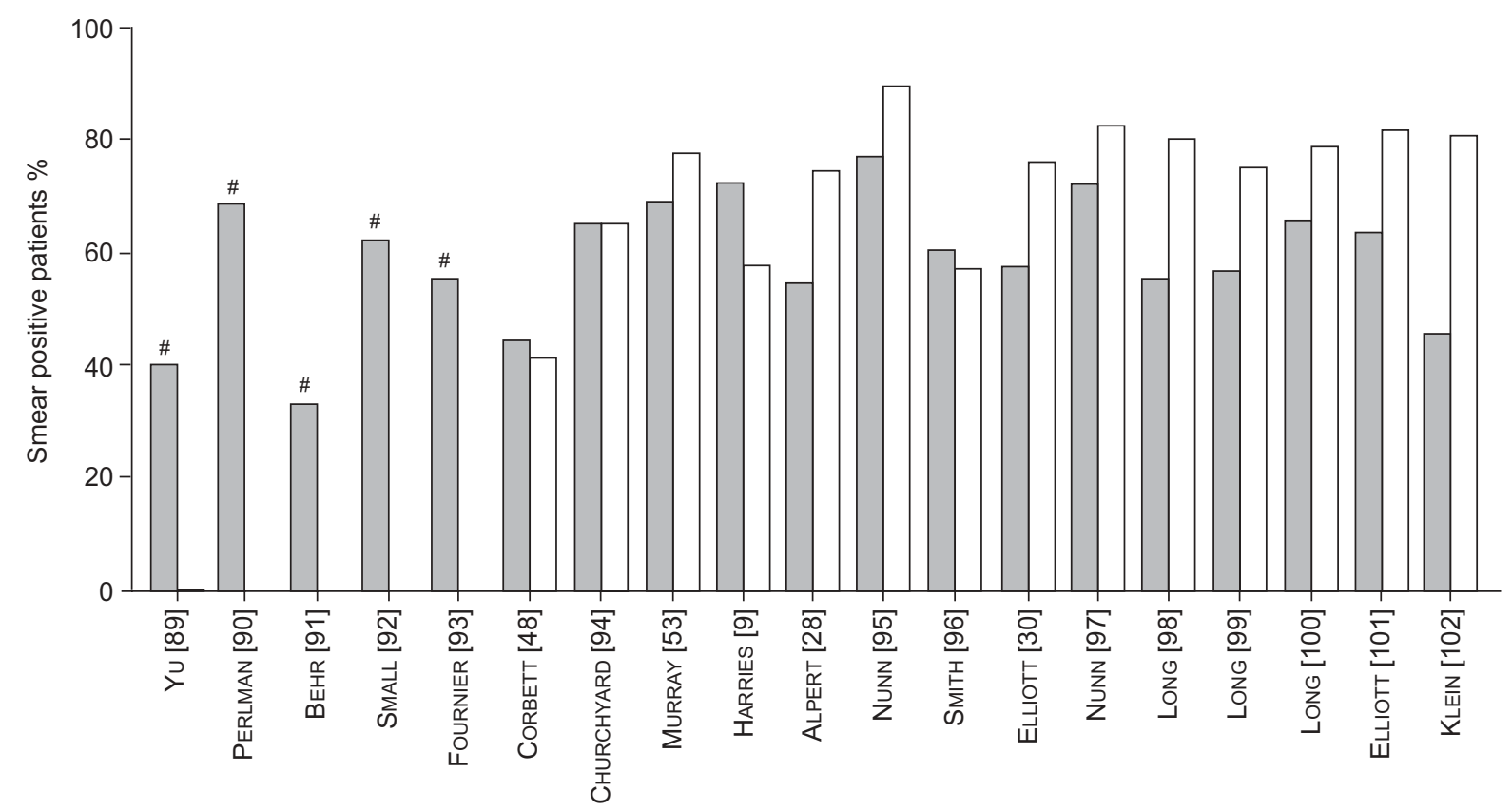

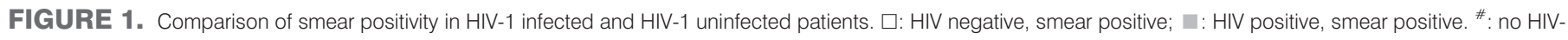
negative comparison groups in these studies. 
TB has tended to be moderate, which limits their diagnostic role $[1118,119]$. The Cepheid GeneXpert system has, however, recently been reported as having $71.7 \%$ sensitivity in smearnegative, culture-positive cases [120] and is under extensive evaluation. This system has two operational advantages: simplicity of sputum processing and the ability to simultaneously detect drug resistance. Rapid detection of rifampicin resistance is also possible on culture or smear-positive specimens with high sensitivity ( $\sim 98 \%$ ) and specificity $(97 \%)$ by the use of line probe assays: two of which are commercially available [121]. The accuracy for INH is more variable, with lower sensitivity $(84.3 \%)$. However, these tests require extensive laboratory support and infrastructure: the generation of amplicon by nested NAAT that is subsequently hybridised to a membrane create conditions in which cross-contamination can be problematic.

An encouraging initial report of $90 \%$ sensitivity of RD1 specific ELISpot in active HIV-1-associated TB [122] prompted a number of evaluations of commercial tests. A wide range of sensitivities have been observed from $23 \%$ to $81 \%$ [74, $123-$ 128]. Indeterminate rates increase as CD4 count declines. Relating the quantitative ELISpot count to CD4 increases the specificity and sensitivity of the diagnosis of active TB in HIV-1 infected persons [74, 129, 130]. However, overall specificity remains poor at $62 \%$, although it could be argued that the finding of a positive IGRA in a HIV-1 infected person should prompt consideration of treating latent infection even if active disease is not found [74].

Commercial and in house serological testing continues to be researched although the consensus is that where adequate sensitivity is achieved this is always at the loss of specificity and few studies have included HIV-1 infected patients [131, 132]. There has been recent interest in the detection of the urinary lipoarabinomannan antigen, particularly in HIV-1 infected persons, as test sensitivity tends to improve with advancing immunosuppression [22] and may, therefore, serve as a potentially useful 'rule-in' tool.

\section{MANAGEMENT OF TB IN HIV-1 INFECTED PERSONS TB therapy}

Duration and effectiveness of TB treatment

The optimal length and type of TB treatment in patients coinfected with HIV-1 is unknown and long-term randomised trials are needed to address this question. Some trials suggest that a 6-month short-course therapy is appropriate in HIV-1 [133-135], whilst others suggest prolonging the duration to 9 months. A retrospective review from the US showed no treatment failures in HIV-1 infected patients administered a 6 month standard rifampicin-based regimen but relapse rates were four-times higher in those treated for 6 months compared to those treated for longer [136]. However, re-infection could not be distinguished from relapse and the dataset was from a small subset of patients as only $17 \%$ of the HIV-1 infected patients (compared to $37 \%$ of the HIV-1 uninfected/unknown group) were given the standard 6-month regimen. Directly observed therapy (DOT) was only prescribed to $57 \%$ of the cases and there were no formal adherence assessments in those not on DOT. Interestingly, HIV-1 infected patients were significantly more likely to experience adverse drug reactions and to acquire drug-resistant TB than the HIV-1-uninfected/ unknown group. A conclusion to be drawn from these data is that when adherence is suboptimal, 6 months of therapy is insufficient.

Further insight comes from a review of six studies of HIV-1 infected patients and three studies of patients without HIV-1 infection given treatment for $\geqslant 6$ months. Unfortunately, there was variability in study design, eligibility criteria, site of TB disease, frequency and method of treatment, and outcome definitions [137]. Although the relapse rates appeared higher in some studies of co-infected patients, other outcomes such as cure rates and successful treatment rates were comparable when 6-month regimens were used. In Brazil, TB recurrence rates were high in HIV-1 infected persons but if there was completion of initial TB therapy, use of ART and subsequent increases in CD4 cell counts then recurrence rates were low, suggesting re-infection may have been the reason for recurrence [138]. Overall, most studies concur that standard TB treatment should be given to HIV-1 infected patients whenever possible $[134,135,139,140]$. A 6-month treatment regimen that includes rifampicin and INH throughout should be given for drug-sensitive TB (outside of the central nervous system). This is usually a regimen of four drugs for 2 months, followed by INH and rifampicin for a further 4 months (at least 182 doses of INH and rifampicin and 56 doses of pyrazinamide and ethambutol in total). Daily TB treatment should be given whenever possible. A recently published systematic review and meta-analysis of treatment studies of active TB in HIV-1 co-infected patients suggested that $\geqslant 8$ months of rifamycin containing treatment with initial daily dosing might be required for optimal treatment outcomes, but concluded that further randomised controlled trials were required to confirm this [141]. In drug-sensitive TB affecting the central nervous system, data supports 9-12 months of treatment. This usually consists of four drugs for 2 months, followed by 7-10 months of INH and rifampicin. MDR- or XDR-TB should be treated by practitioners with experience in such cases and requires prolonged treatment [142, 143].

\section{DIRECTLY OBSERVED THERAPY}

DOT is recommended by the World Health Organization for the treatment of HIV-1/TB, especially if dosing is intermittent. DOT/supervised therapy for ART has been used in some patients but ART has to be administered daily [144]. There have been no randomised controlled trials or systematic reviews on the usefulness of combined ART/TB DOT in treating HIV-1/TB co-infection.

In some circumstances, intermittent therapy can be given three times per week with dose modification $[133,145]$ but it must be via DOT. However, this has caused concern as in one study there was an increased risk of acquired rifamycin resistance in HIV-1-infected patients given three times per week. However, in that study although DOT was used for all doses during the intensive phase, only one dose of three per week was supervised during the continuation phase [146]. Two other DOT strategies used in HIV-1-negative patients have been associated with unacceptably high relapse rates and acquired rifampicin resistance in HIV-1-infected patients and should not be used in this population: these are, once-weekly $\mathrm{INH}-$ rifapentine in the continuation phase, and twice weekly INHrifampicin or INH-rifabutin in patients with CD4 counts 
$<100$ cells $\cdot \mu \mathrm{L}^{-1}[139,147-150]$. In the case of MDR-TB a systematic review and meta-analysis showed higher treatment success when treatment duration was at least 18 months and there was DOT throughout treatment [143].

\section{ROLE OF CORTICOSTEROIDS}

In HIV-1-infected adults with pulmonary or pleural TB, corticosteroids do not improve survival or reduce TB recurrence [151153]. A sub study of HIV-1 infected persons within a randomised controlled trial of dexamethasone for TBM in Vietnam showed a trend towards increased survival in the dexamethasone arm [154]. Most physicians, therefore, give steroids to patients with TB

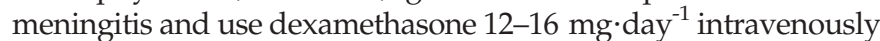
until the patient begins taking medicines orally. An alternative is prednisolone $1.5 \mathrm{mg} \cdot \mathrm{kg}^{-1} \cdot$ day $^{-1}$ for 3 weeks and tapered over the next 3 weeks [155]. A randomised controlled trial of adjunctive prednisolone in HIV-1-infected patients with effusive tuberculous pericarditis demonstrated reduction in mortality among patients who received prednisolone despite the relatively small sample size $(n=58)$ [153].

\section{DRUG-DRUG INTERACTIONS}

Drug-drug interactions between HIV-1 and TB therapy are common and the mechanism is mainly through induction or inhibition of the metabolic family of enzymes in the liver, cytochrome P450 (CYP450). The isoform CYP3A4 is particularly important as it is the main enzyme responsible for the metabolism of protease inhibitors (PI) and non-nucleoside reverse transcriptase inhibitor (NNRTI). Amongst the most potent inducers of CYP3A4 [156, 157] are the rifamycin family and rifampicin (table 2) is the most powerful inducer of CYP3A4 known, with rifabutin less so (table 3) [158]. Rifampicin also induces other cytochromes such as CYP2C19 and CYP2D6 and increases activity of the drug transporter Pglycoprotein that contributes to the absorption, distribution and elimination of PI [159, 160]. Rifabutin, unlike rifampicin, is also a substrate of the CYP3A4 enzyme [156] thus CYP3A4 inhibitors will increase the concentration of rifabutin but have no effect on rifampicin metabolism. As HIV-1 PI are inhibitors of CYP3A4, plasma concentrations of rifabutin and its metabolites may increase and cause toxicity when used with PI [161]. Rifabutin has successfully substituted rifampicin in treating TB in HIV-1-negative patients [162, 163]. It can be used as an alternative to rifampicin to avoid drug interactions. Rifabutin showed similar efficacy to rifampicin in a singleblind, randomised study of $50 \mathrm{HIV}-1$-positive patients in Uganda [164] and a cohort of 25 patients in the US [165]. However, there is a lack of long-term data with rifabutin in HIV-1 infected adults. Rifabutin is expensive though a generic version may soon be developed. Its toxicities include bone marrow suppression, uveitis and arthralgia.

Nucleoside/nucleotide reverse transcriptase inhibitors (NRTI) are mostly metabolised by glucuronidation and are free of clinically significant interactions with rifamycins. Few data are available for the newer antiretroviral agents. Newer drugs such as the CCR5-inhibitors maraviroc and vicriviroc are metabolised by CYP3A4 and thus interact with rifamycins, as does the integrase inhibitor elvitegravir. Raltegravir is metabolised by UGT1A1, which is induced by rifampicin, and studies are underway to clarify the interaction.

\section{RIFAMYCINS AND NNRTIS}

\section{Rifampicin and efavirenz}

There is no consensus about what is the appropriate dose of efavirenz to administer with rifampicin. Several pharmacokinetic studies have found a $20-30 \%$ reduction in efavirenz levels when administered with rifampicin [166, 167] and that, in general, increasing the efavirenz dose from $600 \mathrm{mg}$ to $800 \mathrm{mg}$ is effective and safe [166, 168]. Conversely in cohort studies standard dose efavirenz has been given with rifampicin without compromised clinical efficacy [169-171]. A large cohort study conducted in South Africa showed no difference in rates of virological suppression when comparing patients on efavirenz-containing ART alone and those on efavirenz-containing ART and rifampicin-based TB treatment concurrently. Efavirenz was used at a dose of $600 \mathrm{mg}$ daily irrespective of weight in this cohort [172]. In contrast, an observational cohort looking at pharmacokinetic and clinical outcomes and weight suggested that for patients weighing $>60 \mathrm{~kg}$ a dose of $800 \mathrm{mg}$ efavirenz should be prescribed [173]. One problem is the large interpatient variability in efavirenz levels [174] and this is compounded by the fact that efavirenz levels and toxicity are increased in individuals with polymorphisms in CYP2B6, present in 20\% of the black population compared with $3 \%$ of whites $[175,176]$. This may explain some of the variability and high rates of clinical toxicity in some studies [177]. Based on available data, standard doses of efavirenz can be given to patients weighing $<60 \mathrm{~kg}$, but in patients weighing $>60 \mathrm{~kg}$ an increase to $800 \mathrm{mg}$ daily can be considered although may be unnecessary $[159,178]$. Trough drug level monitoring where available can be performed 2 weeks after starting efavirenz to check adequacy.

\section{Rifampicin and nevirapine}

Rifampicin and nevirapine are both widely used in resource poor countries. Pharmacokinetic data show that nevirapine levels are reduced by $20-55 \%$ by rifampicin [179-183]. As with efavirenz there has been a debate about whether this has any clinical impact. Studies from South Africa and Thailand have found nevirapine levels were significantly reduced by rifampicin in up to a third of patients $[182,183]$. One study aimed to address this issue with patients prescribed $200 \mathrm{mg}$ nevirapine as lead-in dose every $12 \mathrm{~h}$ (rather than the standard $200 \mathrm{mg}$ daily), increasing to $300 \mathrm{mg}$ every $12 \mathrm{~h}$ at 2 weeks (rather than the standard $200 \mathrm{mg}$ every $12 \mathrm{~h}$ ) [184]. The pharmacokinetics was improved in this high-dose group but there was an unacceptably high rate of nevirapine hypersensitivity during the early dosing period. Two studies of clinical outcome have shown high rates of HIV-1 viral suppression with standard dose nevirapine and rifampicin [180, 185]. However, in a large study of 1,283 patients starting ART while on rifampicin (209 people on nevirapine and 1,074 on efavirenz), virological failure rates were almost three times higher in the nevirapine arm compared to the efavirenz or not-on-TB-treatment arms [172]. Interestingly, in a sub-analysis of those patients already on nevirapine who developed incident $\mathrm{TB}$ and then started rifampicin-based TB treatment, virological suppression rates were not compromised [172]. Overall, the data to date suggest that if rifampicin and an NNRTI are to be used then efavirenz is preferred. 
TABLE 2 Pharmacokinetic drug interactions between rifampicin and antiretroviral drugs

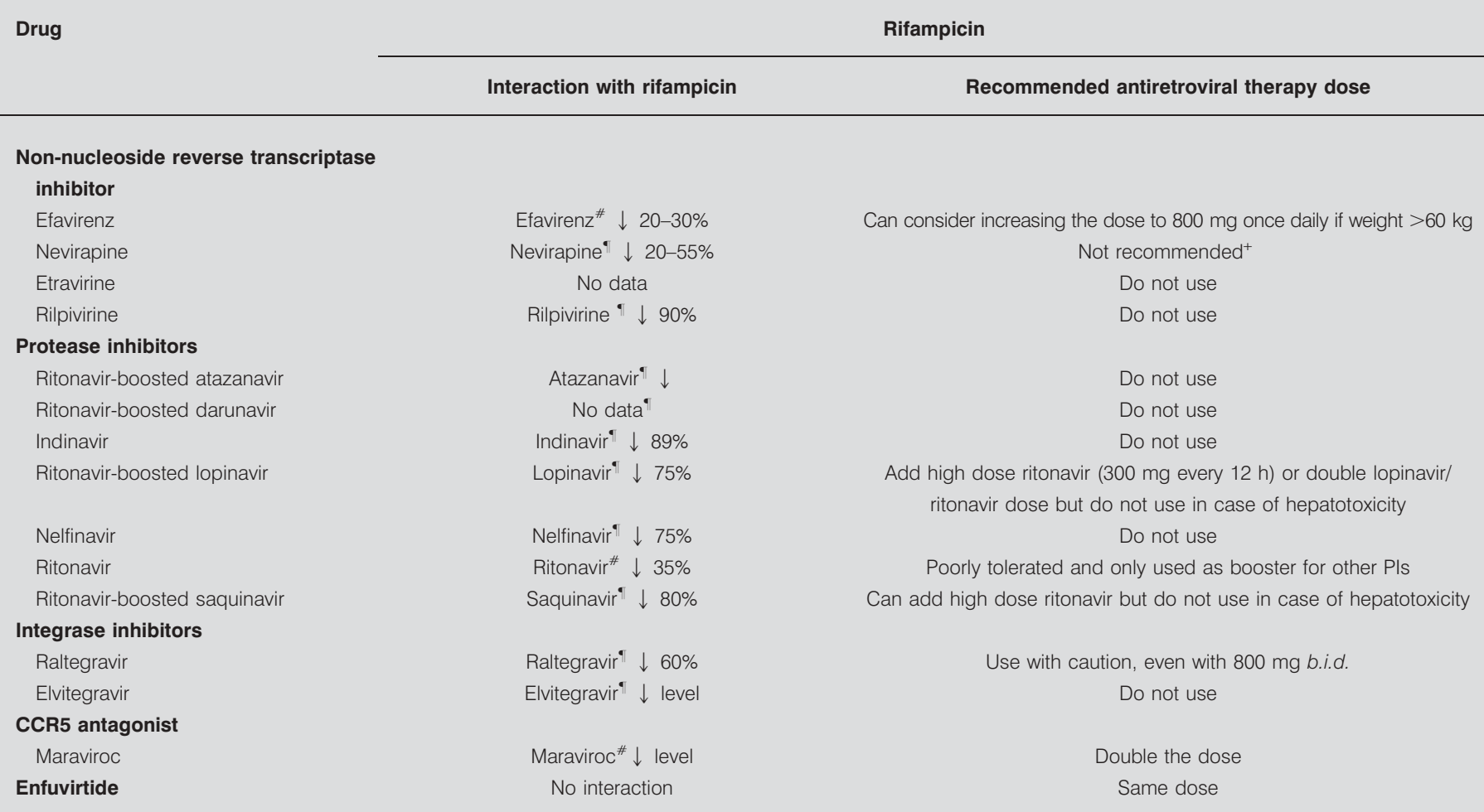

Data for interaction with rifampicin are presented as \% of changes in area under the plasma concentration time curve. ${ }^{*}:$ potential interaction; " : definite interaction, do not combine; ${ }^{+}$: if nevirapine needs to be used, start at $200 \mathrm{mg}$ twice daily (no lead-in dose).

\section{Rifampicin and etravirine or rilpivirine}

No data are available for etravirine and to our knowledge no studies are planned. Based on pharmacokinetic properties they should not be co-administered. Rifampicin reduces plasma concentrations of rilpivirine by up to $90 \%$ so these drugs should also not be used together [186].

\section{RIFABUTIN AND NNRTI}

Efavirenz reduces the area under the plasma concentration time curve (AUC) of rifabutin by $38 \%$ and so the rifabutin dose should be increased to $450 \mathrm{mg}$ daily. Concomitant administration of nevirapine results in nonsignificant changes in nevirapine pharmacokinetics and, based on limited data, rifabutin and nevirapine can probably be given together with no adjustment in either of their doses. Rifabutin and etravirine can be co-prescribed with no dose adjustment. Rifabutin decreases plasma levels of rilpivirine by $50 \%$, and so the dose of rilpivirine should be doubled [186].

\section{RIFAMYCINS AND RITONAVIR-BOOSTED PI}

Most patients are prescribed PI with low dose ritonavir (100 mg or $200 \mathrm{mg}$ daily) to take advantage of ritonavir's CYP3A4 enzyme-inhibiting properties. Ritonavir boosts the concentration of the other PI allowing easier dosing. This property is in contrast to rifampicin's inducing activity which can only be "neutralised" by giving large doses of ritonavir $400 \mathrm{mg}$ b.i.d.

\section{LOPINAVIR/RITONAVIR}

Standard dose ritonavir, as used in the usual dose of lopinavir/ritonavir combination tablets, is not enough to compensate for the inducing effect of rifampicin on lopinavir metabolism [187]. One strategy is to give lopinavir/ritonavir with increased dose ritonavir. In one study when the ritonavir dose was increased to $400 \mathrm{mg}$ twice daily then lopinavir trough concentrations were adequate in nine out of 10 subjects. However, high rates of elevated transaminases, lipid changes and gastrointestinal toxicity were observed [187]. A pharmacokinetic study in healthy volunteers of such a strategy was terminated early because of high rates of severe increase of liver enzymes/transaminases [188]. Another strategy is to double the dose of lopinavir/ritonavir which also overcomes the effect of rifampicin induction [187].

\section{OTHER RITONAVIR-BOOSTED PI}

Saquinavir, atazanavir and tipranavir all have unfavourable pharmacokinetics with rifampicin and should not be administered together. The interaction between darunavir and rifampicin has not been investigated but based on pharmacokinetic properties it should not be co-administered with rifampicin [189-196].

\section{RIFABUTIN AND PI}

\section{Ritonavir boosted PI}

When low-dose ritonavir boosted PI are used with rifabutin there is a complex drug-drug interaction. Rifabutin induces 


\begin{tabular}{|c|c|c|c|}
\hline Drug & \multicolumn{3}{|c|}{ Rifabutin } \\
\hline \multicolumn{4}{|c|}{$\begin{array}{l}\text { Non-nucleoside reverse transcriptase } \\
\text { inhibitor }\end{array}$} \\
\hline Etravirine & & Standard dose with caution & Standard dose \\
\hline Rilpivirine & Rilpivirine $^{\#} \downarrow 50 \%$ & Double dose & Standard dose \\
\hline \multicolumn{4}{|l|}{ Protease inhibitors } \\
\hline Ritonavir- boosted atazanavir & \# & Standard dose & $\begin{array}{c}\downarrow 150 \mathrm{mg} \text { three times per week or } \\
150 \mathrm{mg} \text { daily }\end{array}$ \\
\hline Ritonavir-boosted lopinavir & Rifabutin\# $\uparrow$ AUC 303\% & Standard dose & $\begin{array}{c}\downarrow 150 \mathrm{mg} \text { three times per week or } \\
150 \mathrm{mg} \text { daily }\end{array}$ \\
\hline Nelfinavir & $\begin{array}{c}\text { Nelfinavir }{ }^{\# 250} \text { mg b.i.d. rifabutin } \uparrow \text { AUC } \\
207 \%\end{array}$ & Nelfinavir 1250 mg twice daily & $\begin{array}{c}\downarrow 150 \mathrm{mg} \text { daily or } 150 \mathrm{mg} \text { three times } \\
\text { per week }\end{array}$ \\
\hline Ritonavir & \# & Rifabutin $\uparrow 435 \%$ & $\begin{array}{c}\downarrow 150 \mathrm{mg} \text { three times per week or } \\
150 \mathrm{mg} \text { daily }\end{array}$ \\
\hline Ritonavir-boosted saquinavir & \# & Monitor liver function & $\begin{array}{c}\downarrow 150 \mathrm{mg} \text { three times per week or } \\
150 \mathrm{mg} \text { daily }\end{array}$ \\
\hline \multicolumn{4}{|l|}{ Integrase inhibitors } \\
\hline Raltegravir & & & Standard dose \\
\hline Elvitegravir & No data & & \\
\hline
\end{tabular}

Data for interaction with ributin are presented as \% changes in area under the plasma concentration time curve. AUC: area under the plasma concentration time curve.

${ }^{\#}$ : potential interaction; ${ }^{\natural}$ : no interaction, use standard doses.

the metabolism of the PI but this induction is countered by the inhibitory effects of ritonavir which also inhibit the metabolism of rifabutin. Consequently, the dose of the ritonavir-boosted PI remains unchanged but the dose of rifabutin should be reduced to $150 \mathrm{mg}$ three times per week. There are no clinical outcome data for either HIV-1 or TB using this strategy and, where available, drug levels of the PI should be measured. A recent pharmacokinetic study has raised concerns regarding the current dosing recommendations for rifabutin when used with lopinavir/ritonavir, because of sub therapeutic rifabutin concentrations in the majority of subjects. The authors of that study suggested therapeutic drug monitoring [197]. If physicians consider measuring rifabutin levels this should include determination of the active metabolite, 25-0-desacetyl rifabutin.

\section{PI AND RIFAMYCINS: WHAT TO DO?}

$\mathrm{PI} /$ ritonavir combinations tend not be given with rifampicin, thus, either the ART regimen should be modified to one containing efavirenz if possible or rifabutin should be used instead of rifampicin. In resource-limited settings where rifabutin is not available additional ritonavir boosting of lopinavir has been used with rifampicin. This is done by either adding high-dose ritonavir (additional $300 \mathrm{mg}$ every $12 \mathrm{~h}$ ) to lopinavir/ritonavir combination or by doubling the lopinavir/ritonavir dose to overcome the induction by rifampicin. In healthy volunteer and patient studies, high rates of hepatic events and gastro-intestinal intolerance have been reported with such strategies and patients should be carefully monitored for the development of jaundice or hepatitis [188, 198]. Quadruple nucleosides are also a possibility as ART. The choice of any ART regimen depends on baseline and subsequent resistance testing and history of drug exposure if there has been virological failure.

\section{RIFAMYCINS AND NRTI}

When NRTI are given with rifampicin the pharmacokinetic interactions do not have a significant clinical impact. Triple NRTI regimens are theoretically as attractive as ART because they are free of interactions with TB treatment and have been used in observational studies in Africa [199-201], but have been shown to be virologically inferior to ART containing an NNRTI in a randomised study [202]. Quadruple NRTI regimens (most commonly abacavir, lamivudine, zidovudine and tenofovir) have also been used in adults taking TB treatment [203]. 


\section{RIFAMYCINS AND INTEGRASE INHIBITORS}

Raltegravir is metabolised by UGT1A1 glucuronidation. Rifampicin is an inducer of this enzyme and reduces drug levels of raltegravir [204]. Because the antiviral activity of raltegravir may depend on its AUC, pharmacokinetic data suggests this is maintained if raltegravir dose is doubled when given with rifampicin. Normal doses of raltegravir and rifabutin can be used based on data to date [204]. Elvitegravir is metabolised by CYP3A4 and should not be given with rifampicin.

\section{RIFAMYCINS AND CCR5-ANTAGONISTS OR ENFURVIRTIDE}

As maraviroc is metabolised by CYP3A4 the dose of maraviroc should be doubled to $600 \mathrm{mg}$ b.i.d. when administered with rifampicin [205]. Theoretically, maraviroc can be given at standard doses with rifabutin. There are no significant interactions between rifamycins and enfuvirtide [206].

\section{NON-RIFAMYCIN REGIMENS}

HIV-1 related TB may sometimes be treated with nonrifamycin-containing regimens but these are inferior in efficacy, with high relapse rates [207, 208]. A review of drugdrug interactions between drugs used in non-rifamycin regimens and antiretrovirals describes the potential interactions of these second-line drugs with antiretrovirals [209].

\section{TOXICITY OF COMBINED ART AND TB THERAPY}

Adverse reactions to drugs are common among patients with HIV-1-related TB especially if patients are also taking ART with rash, fever, hepatitis and peripheral neuropathy being common side-effects (table 4). It can be difficult to identify the drug responsible especially if the patient is co-prescribed drugs for opportunistic infection treatment or prophylaxis, such as co-trimoxazole, and the treatments have been started concurrently. High rates of adverse reactions requiring changes in therapy have been reported in HIV-1-infected patients $[210,211]$. High rates of discontinuations of either TB or HIV-1 therapy occur [212, 213] and re-introducing drugs can be prolonged and difficult. This may indirectly increase morbidity and mortality by delaying effective treatment of TB and HIV-1.

\section{HEPATOTOXICITY}

Hepatotoxicity is caused by many drugs used in the treatment of HIV-1, such as co-trimoxazole, azoles and macrolides. Not all reactions are due to $\mathrm{HIV}-1$ or TB drugs. Patients with chronic liver disease have higher rates of toxicity and need more frequent monitoring of liver function tests. Chronic hepatitis B and C are common in HIV-1 infected persons. Acute drug related liver injury or hepatotoxicity is defined as: a serum aspartate aminotransferase (AST) or alanine aminotransferase (ALT) more than three times the upper limit of normal in the presence of symptoms, or a serum AST or ALT more than five times the upper limit of normal in the absence of symptoms. Hepatotoxicity due to INH in the general population increases with age, and is more likely with heavy alcohol intake, hepatitis $\mathrm{C}$ co-infection and in those also on rifampicin.

\section{MANAGEMENT OF HEPATITIS}

All potentially hepatotoxic drugs should be stopped immediately, including INH, rifampicin, pyrazinamide, ART and cotrimoxazole, serology for hepatitis A, B and C should be sent and exposure to other hepatotoxins, including alcohol, should be determined. If resolution of the hepatitis is prolonged then it may be necessary to treat $\mathrm{TB}$ with two or more anti-TB medications without significant risk of hepatotoxicity, such as ethambutol, streptomycin, amikacin/kanamycin, capreomycin or a fluoroquinolone; but not moxifloxacin as it can cause a severe hepatitis. Once the AST drops to less than twice the upper limit of normal and symptoms have significantly improved, first-line TB medications can be restarted. Many physicians use a re-introduction regimen based on common practice but these have not been investigated in clinical trials. If the drugs cannot be restarted or the initial reaction was lifethreatening then an alternative TB regimen should be used. Reintroduction of antivirals has to be with complete regimens as introducing drugs one by one could lead to virological failure. A less hepatotoxic ART regimen may be used when ART is re-introduced.

\section{PERIPHERAL NEUROPATHY}

The nucleoside analogues didanosine and stavudine cause peripheral neuropathy: a toxicity that may be additive when INH is used with stavudine [214, 215]. Thus, stavudine is undesirable if concomitant INH is being administered, although this combination by necessity has been used widely. Patients who develop TB when already taking stavudine should be switched to an alternative antiretroviral, such as tenofovir or zidovudine, if available. All HIV-1-infected patients on $\mathrm{TB}$ treatment should receive supplementary pyridoxine to prevent neuropathy.

\section{RASH}

Rashes are usually mild to moderate and usually occur in the first 2 months of treatment. Mild rashes without mucosal involvement can be treated symptomatically but more widespread or worsening rashes or those with systemic symptoms or mucosal ulceration require drug cessation. In many cases, when the rash has resolved careful drug re-introduction can be performed. There is little prospective data to guide rechallenge. Severe skin reactions to anti-tuberculous therapy should be re-challenged under specialist guidance and aim to re-introduce one drug after the other with gradually escalating doses to aid desensitisation [216]. However, it is not recommended to re-introduce an NNRTI following StevensJohnson syndrome attributed to an NNRTI.

\section{RENAL}

Tenofovir and aminoglycosides used in the treatment of TB (kanamycin, amikacin and streptomycin) are potentially nephrotoxic [217]. All of these drugs predominantly cause toxicity at the level of the proximal renal tubules [218] and it is plausible that simultaneous prescribing of two drugs sharing the same toxic action would increase the risk of nephrotoxicity. The combination of tenofovir with an aminoglycoside should, therefore, be avoided if possible. In patients on an aminoglycoside for the intensive phase of MDR-TB treatment this is an essential part of their treatment, and an alternative antiretroviral to tenofovir should be used during this period. 
TABLE 4 Overlapping or additive toxicities of antiretroviral drugs and anti-tuberculosis (TB) agents

\begin{tabular}{|c|c|c|}
\hline Toxicity & Antiretroviral & Anti-TB \\
\hline Peripheral neuropathy & Stavudine, didanosine & $\mathrm{INH}$, ethionamide and cycloserine \\
\hline Gastrointestinal intolerance & All & All \\
\hline Central nervous system toxicity & Efavirenz & $\mathrm{INH}$, cycloserine, quinolones and ethionamide \\
\hline Bone marrow suppression & Zidovudine & Rifabutin, rifampin and INH \\
\hline Skin rash & $\begin{array}{l}\text { Abacavir, amprenavir, nevirapine, efavirenz, darunavir and } \\
\text { fosamprenavir }\end{array}$ & $\mathrm{INH}$, rifampin and pyrazinamide, ethambutol and streptomycin \\
\hline Renal toxicity & Tenofovir & Aminoglycosides, capreomycin and rifampicin \\
\hline Ocular effects & Didanosine (retinal changes and optic neuritis) & $\begin{array}{l}\text { Ethambutol (optic neuritis or retrobulbar neuritis) } \\
\qquad \text { and rifabutin (uveitis) }\end{array}$ \\
\hline
\end{tabular}

NVP: nevirapine; EFV: efavirenz; PI: protease inhibitors; INH: isoniazid.

\section{WHEN TO START ART}

The World Health Organization 2010 guidelines recommend ART for all HIV-1 infected patients with active TB, irrespective of CD4 cell count. However, the optimal time to start ART in HIV-1/TB patients is incompletely understood and several trials are underway to answer this question [219]. The risk of HIV-1 progression has to be balanced against the hazards of starting ART in patients on anti-TB therapy, which include toxicities, side-effects, immune reconstitution inflammatory syndrome (IRIS) and drug interactions. ART and anti-TB drugs may share similar routes of metabolism and elimination, and extensive drug interactions may also result in sub-therapeutic plasma levels of either or both drugs. Overlapping toxicity may result in the interruption of TB or HIV-1 regimens with subsequent microbiological or virological failure. Deaths may be due to TB especially if occurring early, while late deaths in co-infected persons are usually due to HIV-1 disease progression $[53,96,220]$.

A recent study from South Africa showed a clear mortality benefit in HIV-1/TB who started ART during TB treatment compared to deferring ART until TB treatment was completed. There were 5.4 deaths per 100 person-yrs in the integrated treatment arm and 12.1 per 100 person-yrs in the sequential arm (HR in the integrated-therapy group $0.44, \mathrm{p}=0.003)$. The study included HIV-1 infected patients with CD4 counts $<500$ cells $\cdot \mu \mathrm{L}^{-1}$. The sequential arm of the study was stopped by the data safety monitoring committee and integrated ART was recommended for all patients. TB-IRIS occurred more in the integrated treatment group but the TB-IRIS events did not require changing ART regimen or cause any fatalities and the grade 3 and 4 adverse events (non-IRIS) were similar in both groups [221]. Another South African study of those with low CD4 cell counts starting ART early also showed rates of IRIS are high but mortality is low [222]. A randomised trial recently completed in Cambodia showed a mortality benefit in patients with TB who have a low CD4 count and start ART early. Patients were randomised to start ART either 2 weeks after TB treatment was initiated or 8 weeks later. There was a mortality rate of 8.25 (95\% CI 6.4-10.7) in the early treatment arm and 13.77 (95\% CI 11.2-16.9) in the late treatment arm after 712 person-yrs of follow-up. This was statistically significant $(p=0.02)$ [223]. In contrast, a randomised study of HIV-1 coinfected patients in Vietnam, who were mainly male drug users diagnosed clinically with TB meningitis, compared early (same day as TB treatment) versus deferred ART (2 months after starting TB treatment). It showed no significant differences in outcomes such as deaths at 12 months or AIDS events. There were a significantly increased number of adverse events in the early ART group [224].

Patients with a preserved CD4 count $\left(>350\right.$ cells $\left.\cdot \mu \mathrm{L}^{-1}\right)$ have a lower risk of HIV-1 progression or death during their TB treatment, depending on their age and viral load. In this group ART could be deferred until completion of short-course TB treatment, provided there is both clinical and CD4 count monitoring. This could prevent toxicity and drug interactions. However, most patients with TB present with a low CD4 count, often $<100$ cells $\cdot \mu \mathrm{L}^{-1}$. ART improves survival in these patients and most would advise that ART should be started as soon as practicable $[225,226]$. Some physicians prefer to wait for up to 2 weeks before starting ART after commencing patients on TB treatment to allow diagnosis and management of any early toxicity and adherence problems. Although some groups have not found an advantage of starting ART early $[227,228]$, others have shown that early treatment is associated with decreased mortality and a lowering of the rates of progression [212].

\section{TB-ASSOCIATED IMMUNE RECONSTITUTION INFLAMMATORY SYNDROME}

After the initiation of ART, HIV-1 replication is greatly reduced and viral load rapidly falls. This results in a CD4 Tlymphocyte count increase and immune function improves. When ART is started in patients who are significantly immunosuppressed during the early period of immune recovery a subset may develop IRIS, also termed immune restoration disease [229]. IRIS manifests with clinical deterioration and features of inflammation due to dysregulated immune responses directed to antigens of opportunistic infections, treated or untreated, present prior to ART initiation. IRIS has been described in association with a wide variety of opportunistic infections, but the form that has been most frequently reported and poses the greatest challenge to clinicians globally 
is TB-associated IRIS. TB-IRIS has been reviewed by several authors [230, 231].

TB-IRIS may present as one of two forms. Paradoxical TB-IRIS occurs in patients who are diagnosed with active TB prior to ART, are typically improving on TB treatment and then early during ART develop an immune-mediated paradoxical reaction with new or recurrent clinical and/or radiological manifestations of TB. Less well defined is unmasking TBIRIS, which occurs in a subset of patients diagnosed with active TB while on ART (ART-associated TB) and who present with unusually accelerated or inflammatory features of TB during the first 3 months of ART [231].

\section{PARADOXICAL TB-IRIS}

Paradoxical TB-IRIS has been reported in $8-43 \%$ of patients starting ART while on TB treatment [231]. Most cases of paradoxical TB-IRIS develop during the first 4 weeks of ART [222, 232-235]. Common features are recurrence of TB symptoms, fever, lymphadenitis, enlarging serous effusions, new or recurrent infiltrates on chest radiograph and subcutaneous or deep tissue abscesses [236, 237]. Multiple organ systems may be involved. Patients may experience high fevers, persistent tachycardia and weight loss. The liver may be affected by cholestatic hepatitis due to TB-IRIS, presenting with tender hepatomegaly and cholestatic liver function derangement $[222,237]$. This is difficult to differentiate from drug-induced liver injury. Neurological features, including new or recurrent tuberculous meningitis or enlarging tuberculomas have been reported in $12 \%$ of patients with paradoxical TB-IRIS and may result in death and disability [238].

The major risk factors for paradoxical TB-IRIS are disseminated TB, low CD4 count and shorter interval from start of TB treatment to ART initiation [222, 233-235, 239-241]. The pathogenic mechanism is thought to be an inflammatory reaction to the antigens of mycobacteria still present in tissues despite TB treatment. The duration of paradoxical TB-IRIS is typically $2-3$ months [240, 241], but cases lasting $>1$ yr have been reported [231, 241].

There is no diagnostic test for paradoxical TB-IRIS. The diagnosis is suggested by the following features: improvement on TB treatment prior to ART, deterioration with inflammatory features of TB, a close temporal relationship to ART initiation and exclusion of alternative explanations for deterioration during diagnostic work-up. Alternative diagnoses that need to be considered will depend on the individual case and include: other opportunistic or bacterial infections, malignancy, drugresistant $\mathrm{TB}$, non-adherence to or malabsorption of $\mathrm{TB}$ medication and a drug reaction. In a South African study, the most frequent diagnosis found during work-up was drugresistant TB. Undiagnosed rifampicin resistance was present in nine out of 100 TB-IRIS suspects [236]. Drug susceptibility testing, preferably with a rapid test, should be performed on all paradoxical TB-IRIS suspects.

In some cases the diagnosis is straightforward, such as a patient with proven tuberculous lymphadenitis responding to TB treatment who experiences recurrent night sweats and enlargement of the same lymph node after starting ART. In other cases considerable diagnostic uncertainty may exist. This is particularly the case in resource limited settings where the initial diagnosis of TB is often not microbiologically proven and diagnostic capacity to investigate for alternative diagnoses and drug resistance is limited. In such situations it may not be clear whether deterioration is due to an incorrect diagnosis of TB or TB-IRIS.

A consensus clinical case definition for paradoxical TB-IRIS has been published by the International Network for the Study of HIV-1-associated IRIS (table 5) [231]. This case definition was developed to promote standardisation of research findings from different settings, but it may also be of practical use for clinicians as it provides a systematic approach to diagnose of paradoxical TB-IRIS. This case definition does not include viral load or CD4 criteria because these tests are frequently not available in resource limited settings. Two research groups have independently validated this case definition [237, 242]. The consensus clinical case definition appears to perform as well as a case definition that includes viral load and CD4 cell count criteria which is important, especially in resource limited settings where these variables are often undetermined at the time of presentation with TB-IRIS [237].

Mild cases may require symptomatic therapy only. Aspiration of large fluctuant lymph nodes or soft tissue abscesses may provide symptomatic relief [241]. It is critical to optimise treatment for TB, particularly in cases with drug-resistant TB. Corticosteroids and non-steroidal anti-inflammatory drugs are the most frequently used adjunctive treatments. In a randomised, placebo-controlled trial of prednisone for the treatment of non-life threatening paradoxical TB-IRIS, a 4 -week course of prednisone $\left(1.5 \mathrm{mg} \cdot \mathrm{kg}^{-1} \cdot \mathrm{day}^{-1}\right.$ for 2 weeks followed by 0.75 $\mathrm{mg} \cdot \mathrm{kg}^{-1} \cdot \mathrm{day}^{-1}$ for 2 weeks) significantly reduced a combined primary end-point of number of days hospitalised and number of out-patient therapeutic procedures performed. There was also more rapid symptom improvement in the prednisone arm [243]. Corticosteroids in HIV-1-infected persons are associated with the risk of Kaposi's sarcoma, herpes virus reactivations, other infections and metabolic side-effects [152, 244, 245] and should only be used when the diagnosis of paradoxical TB-IRIS is certain and alternative diagnoses have been excluded.

In most cases, ART should be continued. ART interruption may be considered in life-threatening TB-IRIS, especially when there is severe neurological involvement. Other immunomodulatory treatments, including thalidomide, leukotriene antagonists and tumour necrosis factor- $\alpha$ inhibitors, have been proposed but only isolated case reports of their efficacy exist [230].

\section{UNMASKING TB-IRIS}

High TB incidence rates (5.6-23 TB cases per 100 person-yrs) in the first 3 months of ART have been reported in developing country ART programmes [246, 247]. TB is an important cause of the high mortality observed during early ART in these settings [248].

It has been proposed that a subset of cases of active TB diagnosed on ART represent unmasking TB-IRIS [231, 248]. These are patients who present with heightened inflammatory presentations of TB during the first 3 months of ART. Such patients are assumed to have had undiagnosed or subclinical $\mathrm{TB}$ prior to ART. It is hypothesised that the combination of high mycobacterial organism load and rapid immune recovery favour the development of unmasking TB-IRIS [249]. The few cases that are reported in the literature include patients 


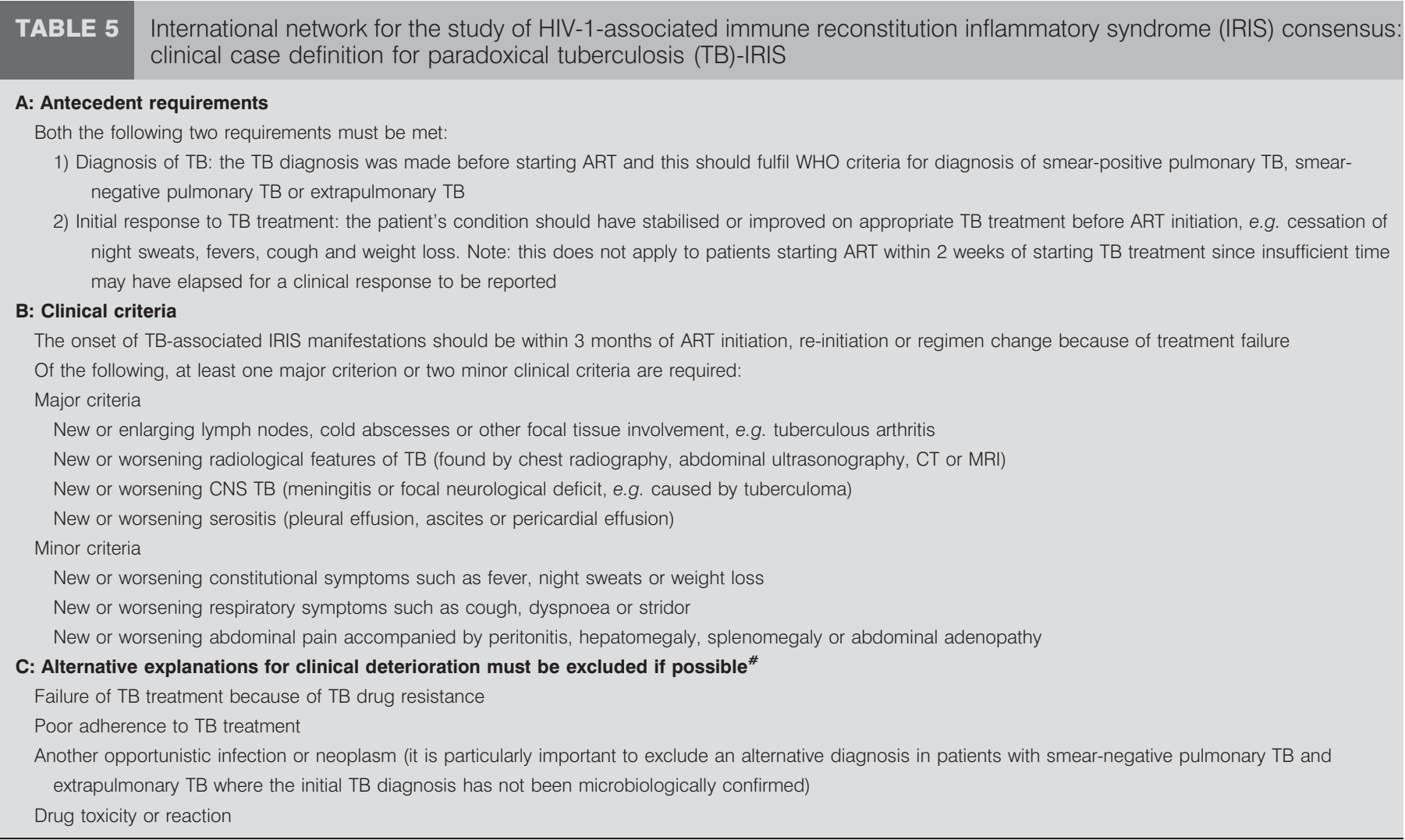

ART: antiretroviral therapy; WHO: World Health Organization; CT: computed tomography; MRI: magnetic resonance imaging; CNS: central nervous system. ${ }^{\#}$ : it might be difficult or impossible in resource-poor settings to confirm TB drug resistance and to exclude certain other infections or neoplasia. Cases where alternative diagnoses cannot be fully excluded because of limited diagnostic capacity should be regarded as "probable paradoxical TB-associated IRIS". In these probable cases, should resolution of clinical or radiological findings of the suspected IRIS episode occur without a change in TB treatment or ART having been made, they could then be reclassified as "paradoxical TB-associated IRIS" cases. Reproduced from [231] with permission from the publisher.

presenting with rapid onset severe pulmonary TB [231, 249, 250], one of whom required mechanical ventilation for adult respiratory distress syndrome associated with miliary TB [250], complicated neurological involvement $[251,252]$ and pyomyositis [253]. A higher mortality in those diagnosed with TB in the first 3 months of ART ( $27 \%$ mortality) compared to other patients with AIDS and TB ( $8 \%$ mortality) was documented in Haiti [254]. This may have been contributed to by unmasking TB-IRIS.

Clinicians should screen for TB symptoms prior to ART, investigate those with symptoms and be aware that some patients with severe immunosuppression may have subclinical active TB [248]. In patients in TB endemic settings or in immigrants from these regions who deteriorate after ART initiation, the diagnosis of unmasking TB-IRIS should be strongly considered. Cases of unmasking TB-IRIS are treated with standard TB treatment. The role of corticosteroids in unmasking TB-IRIS has not been defined.

\section{PREVENTIVE THERAPY AGAINST TB IN HIV-1 INFECTED PERSONS}

Preventive therapy against TB involves treating persons at risk of developing active TB (persons with latent infection with M. tuberculosis) with one or more anti-tuberculous drugs with the aim of eradicating $M$. tuberculosis infection before disease occurs. Evidence indicates that treatment for latent $\mathrm{TB}$ infection reduces the risk of active TB in all HIV-1 infected persons; however, there are two provisos. First, the benefit is only seen in those who are TST positive $(>5 \mathrm{~mm})$ and with a risk ratio of 0.38 compared to those who have a negative tuberculin skin test and a risk ratio of 0.89 [255]. Secondly, the benefits are short-lived in settings of high TB burden. In contrast, IPT is very effective in reducing the risk of TB in countries of low TB incidence [256].

In order to commence a HIV-1 infected person on preventive therapy, active TB needs to be ruled out. This can present difficulties, especially in persons with advanced immunosuppression in areas with high HIV-1 prevalence and TB incidence. Screening for active TB involves symptom screens, microbiological screening, radiological screening or a combination of these tests and, as stated above, all of these may have decreased sensitivity in patients with advanced HIV-1. The yield of intensified case finding in resource-limited settings is predictably associated with the prevalence of HIV-1 in the target population, the local incidence of TB and the screening strategy. When screening only HIV-1 infected populations, substantially higher yields were found when all persons had microbiological screening (sputum test) irrespective of symptoms, consistent 
with a substantial proportion of HIV-1 infected patients who have asymptomatic active TB [19-21, 257]. Screening protocols may, therefore, need to be individualised for different settings according to local and national HIV-1 and TB prevalence and available laboratory and treatment resources.

The current recommended treatment for latent TB in HIV-1 infected persons is 6-9 months of INH monotherapy. Several shorter combinations of anti-tuberculous drugs have also been found to be effective. Efficacy is similar for all regimens but the risk of stopping treatment due to adverse events is significantly higher in the short-course combinations of therapy when compared to INH monotherapy [255]. In HIV-1 uninfected patients the protective effect of TB preventive therapy is long lasting [258]. This has not been observed in HIV-1 infected persons. Several studies from high-burden TB settings showed a fairly rapid waning of the protective effect after stopping TB preventive therapy. In one study the protective effect dissipated after 6 months, suggesting prolonged treatment might be necessary in HIV-1 infected persons [259-261]. A recent large cohort study in Botswana (2,000 HIV-1 infected patients) compared two arms of TB preventive therapy. One arm received 6 months INH monotherapy followed by placebo and the second arm received 3 yrs of continuous INH monotherapy. The study showed a significant decrease in $\mathrm{TB}$ incidence for 36 months in the continuous INH arm compared to the 6-month arm. The protective benefit for the 6-month arm waned 200 days after the INH was stopped. The benefit of INH only occurred in patients who were TST positive although patients who were TST negative were at high risk of developing TB [262].

These findings suggest that even if TST has poor sensitivity to detect latent TB infection in HIV-1 infected persons, it still plays an important role in identifying those HIV-1 infected persons who benefit from long-term TB preventive treatment. It also suggests that those who are TST positive should be on preventive therapy for longer than the currently recommended 6 months. The short-lived IPT induced protection observed in HIV-1 infected persons can be interpreted to indicate that infection pressure in the settings of trials is greater than was experienced in the Bethel studies [258] and, thus, re-infection may be an important factor. An alternative explanation would be that a residual immune response to TB (as manifest by a positive TST) is necessary for IPT to be effective.

In areas with low TB incidence all HIV-1 infected persons should be screened for latent TB infection using TST. IPT should be offered if the test is positive or if the persons are known to be exposed to TB. The recommendation is 9 months of IPT with INH monotherapy.

In areas with high TB incidence all HIV-1 infected individuals should be screened for latent TB infection with TST and those with a positive test should be offered IPT. Long-term IPT may be most effective but has not been systematically evaluated. Also see tables 6 and 7 for summary statement and recommendations.

\section{SUPPORT STATEMENT}

R.J. Wilkinson and G. Meintjes are supported by the Wellcome Trust (references 084323, 081667 and 088316). C. Schutz and G. Meintjes

TABLE 6 Recommendations for prevention and diagnosis of HIV-1 associated tuberculosis (TB)

\section{Low TB incidence region}

Yes
TST
Not essential
$\begin{gathered}\text { Recommend if symptoms present or abnormal } \\ \text { chest radiograph }\end{gathered}$

Should all HIV-1 infected individuals be screened for LTBI?

Preferred screening method?

Symptom screen at every visit?

Sputum TB culture on initial screening?
High TB incidence region

Yes

TST

Strong recommendation

Recommended in all patients where possible, but this is seldom feasible in resource constrained settings

LTBI: latent TB infection; TST: tuberculin skin test.

TABLE 7 Recommendations for treatment of latent tuberculosis infection (LTBI)

\section{Recommendation}

\begin{tabular}{|c|c|}
\hline Should HIV-1 infected person who are TST negative be treated with IPT? & $\begin{array}{c}\text { IPT should be considered regardless of TST result where there has been known } \\
\text { exposure to a smear-positive TB case for a significant time period and in high TB } \\
\text { incidence areas }\end{array}$ \\
\hline What treatment should be given for LTBI? & INH monotherapy \\
\hline How long should patients be treated for LTBI? & $\begin{array}{l}9 \text { months of IPT is adequate in areas with low incidence of TB and high TB incidence } \\
\text { areas long-term (up to } 36 \text { months) IPT should be considered }\end{array}$ \\
\hline
\end{tabular}

TST: tuberculin skin test; IPT: isoniazid preventative therapy; INH: isoniazid. 
received South African TB HIV training (SATBAT) research training which was funded by the Fogarty International Center and National Institute of Health (NIH/FIC 1U2RTW007373-01A1 and U2RTW007370 ICOHRTA). Additional support was provided by the UK and South African Medical Research Councils, and by the European Union (Sante/2006/105-061).

\section{STATEMENT OF INTEREST}

None declared.

\section{ACKNOWLEDGEMENTS}

We would like to thank R. Lehloenya and S. Marais who advised on parts of the manuscript.

\section{REFERENCES}

1 Wood R, Maartens G, Lombard CJ. Risk factors for developing tuberculosis in HIV-1-infected adults from communities with a low or very high incidence of tuberculosis. J Acquir Immune Defic Syndr 2000; 23: 75-80.

2 Burman WJ, Jones BE. Clinical and radiographic features of HIVrelated tuberculosis. Semin Respir Infect 2003; 18: 263-271.

3 Mukadi Y, Perriens JH, St Louis ME, et al. Spectrum of immunodeficiency in HIV-1-infected patients with pulmonary tuberculosis in Zaire. Lancet 1993; 342: 143-146.

4 Sonnenberg P, Glynn JR, Fielding $\mathrm{K}$, et al. How soon after infection with HIV does the risk of tuberculosis start to increase? A retrospective cohort study in South African Gold Miners. J Infect Dis 2005; 191: 150-158.

5 Hopewell PC. Impact of human immunodeficiency virus infection on the epidemiology, clinical features, management, and control of tuberculosis. Clin Infect Dis 1992; 15: 540-547.

6 Wallis RS, Johnson JL. Adult tuberculosis in the 21st century: pathogenesis, clinical features, and management. Curr Opin Pulm Med 2001; 7: 124-132.

7 Jones BE, Young SM, Antoniskis D, et al. Relationship of the manifestations of tuberculosis to CD4 cell counts in patients with human immunodeficiency virus infection. Am Rev Respir Dis 1993; 148: 1292-1297.

8 Raviglione MC, Narain JP, Kochi A. HIV-associated tuberculosis in developing countries: clinical features, diagnosis, and treatment. Bull World Health Organ 1992; 70: 515-526.

9 Harries AD, Maher D, Nunn P. An approach to the problems of diagnosing and treating adult smear-negative pulmonary tuberculosis in high-HIV-prevalence settings in sub-Saharan Africa. Bull World Health Organ 1998; 76: 651-662.

10 Gandhi NR, Shah NS, Andrews JR, et al. HIV coinfection in multidrug- and extensively drug-resistant tuberculosis results in high early mortality. Am J Respir Crit Care Med 2010; 181: $80-86$.

11 Brust JC, Gandhi NR, Carrara $\mathrm{H}$, et al. High treatment failure and default rates for patients with multidrug-resistant tuberculosis in KwaZulu-Natal, South Africa, 2000-2003. Int J Tuberc Lung Dis 2010; 14: 413-419.

12 Bruchfeld J, Aderaye G, Palme IB, et al. Evaluation of outpatients with suspected pulmonary tuberculosis in a high HIV prevalence setting in Ethiopia: clinical, diagnostic and epidemiological characteristics. Scand J Infect Dis 2002; 34: 331-337.

13 Batungwanayo J, Taelman $\mathrm{H}$, Dhote $\mathrm{R}$, et al. Pulmonary tuberculosis in Kigali, Rwanda. Impact of human immunodeficiency virus infection on clinical and radiographic presentation. Am Rev Respir Dis 1992; 146: 53-56.

14 Selwyn PA, Pumerantz AS, Durante A, et al. Clinical predictors of Pneumocystis carinii pneumonia, bacterial pneumonia and tuberculosis in HIV-infected patients. AIDS 1998; 12: 885-893.
15 Kassu A, Mengistu G, Ayele B, et al. Coinfection and clinical manifestations of tuberculosis in human immunodeficiency virus-infected and -uninfected adults at a teaching hospital, northwest Ethiopia. J Microbiol Immunol Infect 2007; 40: 116-122.

16 Garcia GF, Moura AS, Ferreira CS, et al. Clinical and radiographic features of HIV-related pulmonary tuberculosis according to the level of immunosuppression. Rev Soc Bras Med Trop 2007; 40: 622-626.

17 Banda HT, Harries AD, Welby S, et al. Prevalence of tuberculosis in TB suspects with short duration of cough. Trans $R$ Soc Trop Med Hyg 1998; 92: 161-163.

18 Cain KP, McCarthy KD, Heilig CM, et al. An algorithm for tuberculosis screening and diagnosis in people with HIV. N Engl J Med 2010; 362: 707-716.

19 Mtei L, Matee M, Herfort O, et al. High rates of clinical and subclinical tuberculosis among HIV-infected ambulatory subjects in Tanzania. Clin Infect Dis 2005; 40: 1500-1507.

20 Swaminathan S, Paramasivan CN, Kumar SR, et al. Unrecognised tuberculosis in HIV-infected patients: sputum culture is a useful tool. Int J Tuberc Lung Dis 2004; 8: 896-898.

21 Wood R, Middelkoop K, Myer L, et al. Undiagnosed tuberculosis in a community with high HIV prevalence: implications for tuberculosis control. Am J Respir Crit Care Med 2007; 175: 87-93.

22 Lawn SD, Edwards DJ, Kranzer K, et al. Urine lipoarabinomannan assay for tuberculosis screening before antiretroviral therapy diagnostic yield and association with immune reconstitution disease. AIDS 2009; 23: 1875-1880.

23 Bassett Ingrid V, Wang B, Chetty S, et al. Intensive tuberculosis screening for HIV-infected patients starting antiretroviral therapy in Durban, South Africa. Clin Infect Dis 2010; 51: 823-829.

24 Friedland G, Harries A, Coetzee D. Implementation issues in tuberculosis/HIV program collaboration and integration: 3 case studies. J Infect Dis 2007; 196: S114-S123.

25 Kumar P, Sharma N, Sharma NC, et al. Clinical profile of tuberculosis in patients with HIV Infection/AIDS. Indian J Chest Dis Allied Sci 2002; 44: 159-163.

26 Reid MJ, Shah NS. Approaches to tuberculosis screening and diagnosis in people with HIV in resource-limited settings. Lancet Infect Dis 2009; 9: 173-184.

27 Chaisson RE, Schecter GF, Theuer CP, et al. Tuberculosis in patients with the acquired immunodeficiency syndrome. Clinical features, response to therapy, and survival. Am Rev Respir Dis 1987; 136: 570-574.

28 Alpert PL, Munsiff SS, Gourevitch MN, et al. A prospective study of tuberculosis and human immunodeficiency virus infection: clinical manifestations and factors associated with survival. Clin Infect Dis 1997; 24: 661-668.

29 Lucas SB, De Cock KM, Hounnou A, et al. Contribution of tuberculosis to slim disease in Africa. BMJ 1994; 308: 1531-1533.

30 Elliott AM, Halwiindi B, Hayes RJ, et al. The impact of human immunodeficiency virus on presentation and diagnosis of tuberculosis in a cohort study in Zambia. J Trop Med Hyg 1993; 96: 1-11.

31 Sharma SK, Mohan A. Extrapulmonary tuberculosis. Indian J Med Res 2004; 120: 316-353.

32 Pallangyo KJ. Clinical features of tuberculosis among adults in sub-Saharan Africa in the 21st century. Scand J Infect Dis 2001; 33 488-493.

33 Sinkala E, Gray S, Zulu I, et al. Clinical and ultrasonographic features of abdominal tuberculosis in HIV positive adults in Zambia. BMC Infect Dis 2009; 9: 44.

34 McDonald LC, Archibald LK, Rheanpumikankit S, et al. Unrecognised Mycobacterium tuberculosis bacteraemia among hospital inpatients in less developed countries. Lancet 1999; 354: 1159-1163. 
35 Wilson D, Nachega JB, Chaisson RE, et al. Diagnostic yield of peripheral lymph node needle-core biopsies in HIV-infected adults with suspected smear-negative tuberculosis. Int J Tuberc Lung Dis 2005; 9: 220-222.

36 Hill AR, Premkumar S, Brustein S, et al. Disseminated tuberculosis in the acquired immunodeficiency syndrome era. Am Rev Respir Dis 1991; 144: 1164-1170.

37 Vadillo M, Corbella X, Carratala J. AIDS presenting as septic shock caused by Mycobacterium tuberculosis. Scand J Infect Dis 1994; 26: 105-106.

38 Wilson D, Nachega J, Morroni C, et al. Diagnosing smearnegative tuberculosis using case definitions and treatment response in HIV-infected adults. Int J Tuberc Lung Dis 2006; 10: 31-38.

39 Croda MG, Vidal JE, Hernandez AV, et al. Tuberculous meningitis in HIV-infected patients in Brazil: clinical and laboratory characteristics and factors associated with mortality. Int J Infect Dis 2010; 14: e586-e591.

40 Berenguer J, Moreno S, Laguna F, et al. Tuberculous meningitis in patients infected with the human immunodeficiency virus. $N$ Engl J Med 1992; 326: 668-672.

41 Azuaje C, Fernandez Hidalgo N, Almirante B, et al. Tuberculous meningitis: a comparative study in relation to concurrent human immunodeficiency virus infection. Enferm Infecc Microbiol Clin 2006; 24: 245-250.

42 Thwaites GE, Duc Bang N, Huy Dung N, et al. The influence of HIV infection on clinical presentation, response to treatment, and outcome in adults with tuberculous meningitis. J Infect Dis 2005; 192: 2134-2141.

43 Karstaedt AS, Valtchanova S, Barriere R, et al. Tuberculous meningitis in South African urban adults. QJM 1998; 91: 743-747.

44 Yechoor VK, Shandera WX, Rodriguez P, et al. Tuberculous meningitis among adults with and without HIV infection. Experience in an urban public hospital. Arch Intern Med 1996; 156: $1710-1716$

45 Lertsrisatit $\mathrm{P}$, Nantiruj K, Totemchokchyakarn K, et al. Extraspinal tuberculous arthritis in HIV era. Clin Rheumatol 2007; 26: 319-321.

46 Canueto-Quintero J, Caballero-Granado FJ, Herrero-Romero M, et al. Epidemiological, clinical, and prognostic differences between the diseases caused by Mycobacterium kansasii and Mycobacterium tuberculosis in patients infected with human immunodeficiency virus: a multicenter study. Clin Infect Dis 2003; 37: 584-590.

47 Ntsekhe M, Wiysonge CS, Gumedze F, et al. HIV infection is associated with a lower incidence of constriction in presumed tuberculous pericarditis: a prospective observational study. PLoS One 2008; 3: e2253.

48 Corbett EL, Charalambous S, Moloi VM, et al. Human immunodeficiency virus and the prevalence of undiagnosed tuberculosis in African gold miners. Am J Respir Crit Care Med 2004; 170: 673-679.

49 Corbett EL, Bandason T, Cheung YB, et al. Prevalent infectious tuberculosis in Harare, Zimbabwe: burden, risk factors and implications for control. Int J Tuberc Lung Dis 2009; 13: 1231-1237.

50 Nyamande K, Lalloo UG, John M. TB presenting as communityacquired pneumonia in a setting of high TB incidence and high HIV prevalence. Int J Tuberc Lung Dis 2007; 11: 1308-1313.

51 Lawn SD, Harries AD, Wood R. Strategies to reduce early morbidity and mortality in adults receiving antiretroviral therapy in resource-limited settings. Curr Opin HIV AIDS 2010; 5: 18-26.

52 Rana FS, Hawken MP, Mwachari C, et al. Autopsy study of HIV-1-positive and HIV-1-negative adult medical patients in Nairobi, Kenya. J Acquir Immune Defic Syndr 2000; 24: 23-29.
53 Murray J, Sonnenberg P, Shearer S, et al. Human immunodeficiency virus and the outcome of treatment for new and recurrent pulmonary tuberculosis in African patients. Am J Respir Crit Care Med 1999; 159: 733-740.

54 Schmaltz CA, Sant'Anna FM, Neves SC, et al. Influence of HIV infection on mortality in a cohort of patients treated for tuberculosis in the context of wide access to HAART, in Rio de Janeiro, Brazil. J Acquir Immune Defic Syndr 2009; 52: 623-628.

55 Elliott AM, Halwiindi B, Hayes RJ, et al. The impact of human immunodeficiency virus on mortality of patients treated for tuberculosis in a cohort study in Zambia. Trans $R$ Soc Trop Med Hyg 1995; 89: 78-82.

56 Young DB, Gideon HP, Wilkinson RJ. Eliminating latent tuberculosis. Trends Microbiol 2009; 17: 183-188.

57 Barry 3rd CE, Boshoff HI, Dartois V, et al. The spectrum of latent tuberculosis: rethinking the biology and intervention strategies. Nat Rev Microbiol 2009; 7: 845-855.

58 Mack U, Migliori GB, Sester M, et al. LTBI: latent tuberculosis infection or lasting immune responses to M. tuberculosis? A TBNET consensus statement. Eur Respir J 2009; 33: 956-973.

59 Corbett EL, Bandason T, Cheung YB, et al. Epidemiology of tuberculosis in a high HIV prevalence population provided with enhanced diagnosis of symptomatic disease. PLoS Med 2007; 4: e22.

60 Hawken M, Nunn P, Gathua S, et al. Increased recurrence of tuberculosis in HIV-1-infected patients in Kenya. Lancet 1993; 342: 332-337.

61 Selwyn PA, Hartel D, Lewis VA, et al. A prospective study of the risk of tuberculosis among intravenous drug users with human immunodeficiency virus infection. N Engl J Med 1989; 320: 545-550.

62 Glynn JR, Crampin AC, Ngwira BM, et al. Trends in tuberculosis and the influence of HIV infection in northern Malawi, 19882001. AIDS 2004; 18: 1459-1463.

63 Alland D, Kalkut GE, Moss AP, et al. Transmission of tuberculosis in New York City. An analysis by DNA fingerprinting and conventional epidemiologic methods. N Engl J Med 1994; 330: 1710-1716.

64 Maartens G, Wilkinson RJ. Tuberculosis. Lancet 2007; 370: 2030-2043.

65 Graham NM, Nelson KE, Solomon L, et al. Prevalence of tuberculin positivity and skin test anergy in HIV-1-seropositive and seronegative intravenous drug users. JAMA 1992; 267: 369-373.

66 Selwyn PA, Sckell BM, Alcabes P, et al. High risk of active tuberculosis in HIV-infected drug users with cutaneous anergy. JAMA 1992; 268: 504-509.

67 Markowitz N, Hansen NI, Wilcosky TC, et al. Tuberculin and anergy testing in HIV-seropositive and HIV-seronegative persons. Pulmonary complications of HIV Infection Study Group. Ann Intern Med 1993; 119: 185-193.

68 Rangaka MX, Wilkinson KA, Seldon R, et al. Effect of HIV-1 infection on T-cell-based and skin test detection of tuberculosis infection. Am J Respir Crit Care Med 2007; 175: 514-520.

69 Sorensen AL, Nagai S, Houen G, et al. Purification and characterization of a low-molecular-mass T-cell antigen secreted by Mycobacterium tuberculosis. Infect Immun 1995; 63: 1710-1717.

70 Berthet FX, Rasmussen PB, Rosenkrands I, et al. A Mycobacterium tuberculosis operon encoding ESAT-6 and a novel low-molecularmass culture filtrate protein (CFP-10). Microbiology 1998; 144: 3195-3203.

71 Aagaard C, Brock I, Olsen A, et al. Mapping immune reactivity toward Rv2653 and Rv2654: two novel low-molecular-mass antigens found specifically in the Mycobacterium tuberculosis complex. J Infect Dis 2004; 189: 812-819.

72 Van Zyl-Smit RN, Pai M, Peprah K, et al. Within-subject variability and boosting of $\mathrm{T}$-cell interferon-gamma responses after tuberculin skin testing. Am J Respir Crit Care Med 2009; 180: $49-58$. 
73 Pai M, Zwerling A, Menzies D. Systematic review: T-cell-based assays for the diagnosis of latent tuberculosis infection: an update. Ann Intern Med 2008; 149: 177-184.

74 Oni T, Patel J, Gideon HP, et al. Enhanced diagnosis of HIV-1 associated tuberculosis by relating T-SPOT.TB and CD4 counts. Eur Respir J 2010; 36: 594-600.

75 Millington KA, Innes JA, Hackforth S, et al. Dynamic relationship between IFN- $\gamma$ and IL-2 profile of Mycobacterium tuberculosisspecific T cells and antigen load. J Immunol 2007; 178: 5217-5226.

76 Dietrich J, Andersen C, Rappuoli R, et al. Mucosal administration of Ag85B-ESAT-6 protects against infection with Mycobacterium tuberculosis and boosts prior bacillus Calmette-Guerin immunity. J Immunol 2006; 177: 6353-6360.

77 Vordermeier HM, Chambers MA, Cockle PJ, et al. Correlation of ESAT-6-specific gamma interferon production with pathology in cattle following Mycobacterium bovis BCG vaccination against experimental bovine tuberculosis. Infect Immun 2002; 70: 3026-3032.

78 Ribeiro S, Dooley K, Hackman J, et al. T-SPOT.TB responses during treatment of pulmonary tuberculosis. BMC Infect Dis 2009; 9: 23.

79 Leidl L, Mayanja-Kizza H, Sotgiu G, et al. Relationship of immunodiagnostic assays for tuberculosis and numbers of circulating CD4+T-cells in HIV infection. Eur Respir J 2010; 35: 619-626.

80 Sester M, Giehl C, Sester U, et al. Management of tuberculosis in HIV infection: where T-cells matter. Eur Respir J 2010; 35: 475-476.

81 Aichelburg MC, Rieger A, Breitenecker F, et al. Detection and prediction of active tuberculosis disease by a whole-blood interferon-gamma release assay in HIV-1-infected individuals. Clin Infect Dis 2009; 48: 954-962.

82 Brock I, Ruhwald M, Lundgren B, et al. Latent tuberculosis in HIV positive, diagnosed by the $M$. tuberculosis specific interferon-gamma test. Respir Res 2006; 7: 56.

83 Jones S, de Gijsel D, Wallach FR, et al. Utility of QuantiFERONTB Gold in-tube testing for latent TB infection in HIV-infected individuals. Int J Tuberc Lung Dis 2007; 11: 1190-1195.

84 Luetkemeyer AF, Charlebois ED, Flores LL, et al. Comparison of an interferon-gamma release assay with tuberculin skin testing in HIV-infected individuals. Am J Respir Crit Care Med 2007; 175: 737-742.

85 Richeldi L, Losi M, D'Amico R, et al. Performance of tests for latent tuberculosis in different groups of immunocompromised patients. Chest 2009; 136: 198-204.

86 Talati NJ, Seybold U, Humphrey B, et al. Poor concordance between interferon-gamma release assays and tuberculin skin tests in diagnosis of latent tuberculosis infection among HIVinfected individuals. BMC Infect Dis 2009; 9: 15.

87 Stephan C, Wolf T, Goetsch U, et al. Comparing QuantiFERONtuberculosis gold, T-SPOT tuberculosis and tuberculin skin test in HIV-infected individuals from a low prevalence tuberculosis country. AIDS 2008; 22: 2471-2479.

88 Perkins MD. New diagnostic tools for tuberculosis. Int J Tuberc Lung Dis 2000; 4: Suppl. 2, S182-S188.

$89 \mathrm{Yu} \mathrm{JK}$, Bong CN, Chen SC, et al. Outcomes in HIV-infected patients who develop tuberculosis after starting antiretroviral treatment in Malawi. Int J Tuberc Lung Dis 2008; 12: 692-694.

90 Perlman DC, el-Sadr WM, Nelson ET, et al. Variation of chest radiographic patterns in pulmonary tuberculosis by degree of human immunodeficiency virus-related immunosuppression. The Terry Beirn Community Programs for Clinical Research on AIDS (CPCRA). The AIDS Clinical Trials Group (ACTG). Clin Infect Dis 1997; 25: 242-246.

91 Behr MA, Warren SA, Salamon $\mathrm{H}$, et al. Transmission of Mycobacterium tuberculosis from patients smear-negative for acid-fast bacilli. Lancet 1999; 353: 444-449.
92 Small PM, Schecter GF, Goodman PC, et al. Treatment of tuberculosis in patients with advanced human immunodeficiency virus infection. N Engl J Med 1991; 324: 289-294.

93 Fournier AM, Dickinson GM, Erdfrocht IR, et al. Tuberculosis and nontuberculous mycobacteriosis in patients with AIDS Chest 1988; 93: 772-775.

94 Churchyard GJ, Kleinschmidt I, Corbett EL, et al. Mycobacterial disease in South African gold miners in the era of HIV infection. Int J Tuberc Lung Dis 1999; 3: 791-798.

95 Nunn P, Mungai M, Nyamwaya J, et al. The effect of human immunodeficiency virus type- 1 on the infectiousness of tuberculosis. Tuber Lung Dis 1994; 75: 25-32.

96 Smith RL, Yew K, Berkowitz KA, et al. Factors affecting the yield of acid-fast sputum smears in patients with HIV and tuberculosis. Chest 1994; 106: 684-686.

97 Nunn P, Brindle R, Carpenter L, et al. Cohort study of human immunodeficiency virus infection in patients with tuberculosis in Nairobi, Kenya. Analysis of early (6-month) mortality. Am Rev Respir Dis 1992; 146: 849-854.

98 Long R, Maycher B, Scalcini M, et al. The chest roentgenogram in pulmonary tuberculosis patients seropositive for human immunodeficiency virus type 1. Chest 1991; 99: 123-127.

99 Long R, Scalcini M, Manfreda J, et al. Impact of human immunodeficiency virus type 1 on tuberculosis in rural Haiti. Am Rev Respir Dis 1991; 143: 69-73.

100 Long R, Scalcini M, Manfreda J, et al. The impact of HIV on the usefulness of sputum smears for the diagnosis of tuberculosis Am J Public Health 1991; 81: 1326-1328.

101 Elliott AM, Luo N, Tembo G, et al. Impact of HIV on tuberculosis In Zambia: a cross sectional study. BMJ 1990; 301: 412-415.

102 Klein NC, Duncanson FP, Lenox TH 3rd, et al. Use of mycobacterial smears in the diagnosis of pulmonary tuberculosis in AIDS/ARC patients. Chest 1989; 95: 1190-1192.

103 Furin JJ, Johnson JL. Recent advances in the diagnosis and management of tuberculosis. Curr Opin Pulm Med 2005; 11: 189-194.

104 Steingart KR, Henry M, Ng V, et al. Fluorescence versus conventional sputum smear microscopy for tuberculosis: a systematic review. Lancet Infect Dis 2006; 6: 570-581.

105 Marais BJ, Brittle W, Painczyk K, et al. Use of light-emitting diode fluorescence microscopy to detect acid-fast bacilli in sputum. Clin Infect Dis 2008; 47: 203-207.

106 Lillehei JP. Sputum induction with heated aerosol inhalations for the diagnosis of tuberculosis. Am Rev Respir Dis 1961; 84 276-278.

107 Hartung TK, Maulu A, Nash J, et al. Suspected pulmonary tuberculosis in rural South Africa: sputum induction as a simple diagnostic tool? S Afr Med J 2002; 92: 455-458.

108 Parry CM, Kamoto O, Harries AD, et al. The use of sputum induction for establishing a diagnosis in patients with suspected pulmonary tuberculosis in Malawi. Tuber Lung Dis 1995; 76: 72-76.

109 Post FA, Wood R, Pillay GP. Pulmonary tuberculosis in HIV infection: radiographic appearance is related to CD4+T-lymphocyte count. Tuber Lung Dis 1995; 76: 518-521.

110 World Health Organization. Improving the diagnosis and treatment of smear-negative pulmonary and extrapulmonary tuberculosis among adults and adolescents. Recommendations for HIV-prevalent and resource constrained settings. Geneva, World Health Organization, 2006. www.who.int/tb/publications/2006/tbhiv_recommendations.pdf

111 Colebunders R, Bastian I. A review of the diagnosis and treatment of smear-negative pulmonary tuberculosis. Int $J$ Tuberc Lung Dis 2000; 4: 97-107.

112 Siddiqi K, Lambert ML, Walley J. Clinical diagnosis of smearnegative pulmonary tuberculosis in low-income countries: the current evidence. Lancet Infect Dis 2003; 3: 288-296. 
113 Saltini C. Chemotherapy and diagnosis of tuberculosis. Respir Med 2006; 100: 2085-2097.

114 Williams-Bouyer N, Yorke R, Lee HI, et al. Comparison of the BACTEC MGIT 960 and ESP culture system II for growth and detection of mycobacteria. J Clin Microbiol 2000; 38: 4167-4170.

115 Caviedes L, Lee TS, Gilman RH, et al. Rapid, efficient detection and drug susceptibility testing of Mycobacterium tuberculosis in sputum by microscopic observation of broth cultures. The Tuberculosis Working Group in Peru. J Clin Microbiol 2000; 38: 1203-1208.

116 Caws M, Dang TM, Torok E, et al. Evaluation of the MODS culture technique for the diagnosis of tuberculous meningitis. PLoS One 2007; 2: e1173.

117 Moore DA, Evans CA, Gilman RH, et al. Microscopic-observation drug-susceptibility assay for the diagnosis of TB. N Engl J Med 2006; 355: 1539-1550.

118 Flores LL, Pai M, Colford JM Jr, et al. In-house nucleic acid amplification tests for the detection of Mycobacterium tuberculosis in sputum specimens: meta-analysis and meta-regression. BMC Microbiol 2005; 5: 55.

119 Ling DI, Flores LL, Riley LW, et al. Commercial nucleic-acid amplification tests for diagnosis of pulmonary tuberculosis in respiratory specimens: meta-analysis and meta-regression. PLoS One 2008; 3: e1536.

120 Helb D, Jones M, Story E, et al. Rapid detection of Mycobacterium tuberculosis and rifampin resistance by use of on-demand, nearpatient technology. J Clin Microbiol 2010; 48: 229-237.

121 Ling DI, Zwerling AA, Pai M. GenoType MTBDR assays for the diagnosis of multidrug-resistant tuberculosis: a meta-analysis. Eur Respir J 2008; 32: 1165-1174.

122 Chapman AL, Munkanta M, Wilkinson KA, et al. Rapid detection of active and latent tuberculosis infection in HIV-positive individuals by enumeration of Mycobacterium tuberculosis-specific T cells. AIDS 2002; 16: 2285-2293.

123 Baba K, Sornes S, Hoosen AA, et al. Evaluation of immune responses in HIV infected patients with pleural tuberculosis by the QuantiFERON TB-Gold interferon-gamma assay. BMC Infect Dis 2008; 8: 35.

124 Cattamanchi A, Ssewenyana I, Davis JL, et al. Role of interferongamma release assays in the diagnosis of pulmonary tuberculosis in patients with advanced HIV infection. BMC Infect Dis 2010; 10: 75 .

125 Raby E, Moyo M, Devendra A, et al. The effects of HIV on the sensitivity of a whole blood IFN-gamma release assay in Zambian adults with active tuberculosis. PLoS One 2008; 3: e2489.

126 Seshadri C, Uiso LO, Ostermann J, et al. Low sensitivity of T-cell based detection of tuberculosis among HIV co-infected Tanzanian in-patients. East Afr Med J 2008; 85: 442-449.

127 Syed Ahamed Kabeer B, Sikhamani R, Swaminathan S, et al. Role of interferon gamma release assay in active TB diagnosis among HIV infected individuals. PLoS One 2009; 4: e5718.

128 Tsiouris SJ, Coetzee D, Toro PL, et al. Sensitivity analysis and potential uses of a novel gamma interferon release assay for diagnosis of tuberculosis. J Clin Microbiol 2006; 44: 2844-2850.

129 Clark SA, Martin SL, Pozniak A, et al. Tuberculosis antigenspecific immune responses can be detected using enzyme-linked immunospot technology in human immunodeficiency virus (HIV)-1 patients with advanced disease. Clin Exp Immunol 2007; 150: 238-244.

130 Rangaka MX, Diwakar L, Seldon R, et al. Clinical, immunological, and epidemiological importance of antituberculosis $\mathrm{T}$ cell responses in HIV-infected Africans. Clin Infect Dis 2007; 44: 1639-1646.

131 Steingart KR, Dendukuri N, Henry $M$, et al. Performance of purified antigens for serodiagnosis of pulmonary tuberculosis: a meta-analysis. Clin Vaccine Immunol 2009; 16: 260-276.
132 Steingart KR, Henry M, Laal S, et al. Commercial serological antibody detection tests for the diagnosis of pulmonary tuberculosis: a systematic review. PLoS Med 2007; 4: e202.

133 Chaisson RE, Clermont HC, Holt EA, et al. Six-month supervised intermittent tuberculosis therapy in Haitian patients with and without HIV infection. Am J Respir Crit Care Med 1996; 154: 1034-1038.

134 Sterling TR, Alwood K, Gachuhi R, et al. Relapse rates after short-course (6-month) treatment of tuberculosis in HIV-infected and uninfected persons. AIDS 1999; 13: 1899-1904.

135 Kassim S, Sassan-Morokro M, Ackah A, et al. Two-year followup of persons with HIV-1- and HIV-2-associated pulmonary tuberculosis treated with short-course chemotherapy in West Africa. AIDS 1995; 9: 1185-1191.

136 Nahid P, Gonzalez LC, Rudoy I, et al. Treatment outcomes of patients with HIV and tuberculosis. Am J Respir Crit Care Med 2007; 175: 1199-1206.

137 El-Sadr WM, Perlman DC, Denning E, et al. A review of efficacy studies of 6-month short-course therapy for tuberculosis among patients infected with human immunodeficiency virus: differences in study outcomes. Clin Infect Dis 2001; 32: 623-632.

138 Golub JE, Durovni B, King BS, et al. Recurrent tuberculosis in HIV-infected patients in Rio de Janeiro, Brazil. AIDS 2008; 22: 2527-2533.

139 El-Sadr WM, Perlman DC, Matts JP, et al. Evaluation of an intensive intermittent-induction regimen and duration of shortcourse treatment for human immunodeficiency virus-related pulmonary tuberculosis. Terry Beirn Community Programs for Clinical Research on AIDS (CPCRA) and the AIDS Clinical Trials Group (ACTG). Clin Infect Dis 1998; 26: 1148-1158.

140 Chemotherapy and management of tuberculosis in the United Kingdom: recommendations 1998. Joint Tuberculosis Committee of the British Thoracic Society. Thorax 1998; 53: 536-548.

141 Khan FA, Minion J, Pai M, et al. Treatment of active tuberculosis in HIV-coinfected patients: a systematic review and metaanalysis. Clin Infect Dis 2010; 50: 1288-1299.

142 Sotgiu G, Centis R, D'Ambrosio L, et al. Development of a standardised tool to survey MDR-/XDR-TB case management in Europe. Eur Respir J 2010; 36: 208-211.

143 Orenstein EW, Basu S, Shah NS, et al. Treatment outcomes among patients with multidrug-resistant tuberculosis: systematic review and meta-analysis. Lancet Infect Dis 2009; 9: 153-161.

144 Farmer P, Leandre F, Mukherjee J, et al. Community-based treatment of advanced HIV disease: introducing DOT-HAART (directly observed therapy with highly active antiretroviral therapy). Bull World Health Organ 2001; 79: 1145-1151.

145 Alwood K, Keruly J, Moore-Rice K, et al. Effectiveness of supervised, intermittent therapy for tuberculosis in HIV-infected patients. AIDS 1994; 8: 1103-1108.

146 Swaminathan S, Narendran G, Venkatesan $P$, et al. Acquired rifampicin resistance in HIV-infected and -uninfected patients with TB treated with a thrice-weekly short-course regimen. Abstract 783. 16th Conference on Retrovirusses and Opportunistic Infections, Montreal, Canada, 2009.

147 Acquired rifamycin resistance in persons with advanced HIV disease being treated for active tuberculosis with intermittent rifamycin-based regimens. MMWR Morb Mortal Wkly Rep 2002; 51: $214-215$

148 Vernon A, Burman W, Benator D, et al. Acquired rifamycin monoresistance in patients with HIV-related tuberculosis treated with once-weekly rifapentine and isoniazid. Tuberculosis Trials Consortium. Lancet 1999; 353: 1843-1847.

149 Nettles RE, Mazo D, Alwood K, et al. Risk factors for relapse and acquired rifamycin resistance after directly observed tuberculosis treatment: a comparison by HIV serostatus and rifamycin use. Clin Infect Dis 2004; 38: 731-736. 
150 Burman W, Benator D, Vernon A, et al. Acquired rifamycin resistance with twice-weekly treatment of HIV-related tuberculosis. Am J Respir Crit Care Med 2006; 173: 350-356.

151 Mayanja-Kizza H, Jones-Lopez E, Okwera A, et al. Immunoadjuvant prednisolone therapy for HIV-associated tuberculosis: a phase 2 clinical trial in Uganda. J Infect Dis 2005; 191: 856-865.

152 Elliott AM, Luzze H, Quigley MA, et al. A randomized, doubleblind, placebo-controlled trial of the use of prednisolone as an adjunct to treatment in HIV-1-associated pleural tuberculosis. J Infect Dis 2004; 190: 869-878.

153 Hakim JG, Ternouth I, Mushangi E, et al. Double blind randomised placebo controlled trial of adjunctive prednisolone in the treatment of effusive tuberculous pericarditis in HIV seropositive patients. Heart 2000; 84: 183-188.

154 Thwaites GE, Nguyen DB, Nguyen HD, et al. Dexamethasone for the treatment of tuberculous meningitis in adolescents and adults. N Engl J Med 2004; 351: 1741-1751.

155 Prasad K, Singh MB. Corticosteroids for managing tuberculous meningitis. Cochrane Database Syst Rev 2008; 1: CD002244.

$156 \mathrm{Li} \mathrm{AP}$, Reith MK, Rasmussen A, et al. Primary human hepatocytes as a tool for the evaluation of structure-activity relationship in cytochrome P450 induction potential of xenobiotics: evaluation of rifampin, rifapentine and rifabutin. Chem Biol Interact 1997; 107: 17-30.

157 Rae JM, Johnson MD, Lippman ME, et al. Rifampin is a selective, pleiotropic inducer of drug metabolism genes in human hepatocytes: studies with cDNA and oligonucleotide expression arrays. J Pharmacol Exp Ther 2001; 299: 849-857.

158 Perucca E, Grimaldi R, Frigo GM, et al. Comparative effects of rifabutin and rifampicin on hepatic microsomal enzyme activity in normal subjects. Eur J Clin Pharmacol 1988; 34: 595-599.

159 Maartens G, Decloedt E, Cohen K. Effectiveness and safety of antiretrovirals with rifampicin: crucial issues for high-burden countries. Antivir Ther 2009; 14: 1039-1043.

160 Schuetz EG, Schinkel AH, Relling MV, et al. P-glycoprotein: a major determinant of rifampicin-inducible expression of cytochrome P4503A in mice and humans. Proc Natl Acad Sci USA 1996; 93: 4001-4005.

161 Davies G, Cerri S, Richeldi L. Rifabutin for treating pulmonary tuberculosis. Cochrane Database Syst Rev 2007; 4: CD005159.

162 Gonzalez-Montaner LJ, Natal S, Yongchaiyud P, et al. Rifabutin for the treatment of newly-diagnosed pulmonary tuberculosis: a multinational, randomized, comparative study versus Rifampicin. Rifabutin Study Group. Tuber Lung Dis 1994; 75: 341-347.

163 McGregor MM, Olliaro P, Wolmarans L, et al. Efficacy and safety of rifabutin in the treatment of patients with newly diagnosed pulmonary tuberculosis. Am J Respir Crit Care Med 1996; 154: 1462-1467.

164 Schwander S, Rusch-Gerdes S, Mateega A, et al. A pilot study of antituberculosis combinations comparing rifabutin with rifampicin in the treatment of HIV-1 associated tuberculosis. A singleblind randomized evaluation in Ugandan patients with HIV-1 infection and pulmonary tuberculosis. Tuber Lung Dis 1995; 76: 210-218.

165 Narita M, Stambaugh JJ, Hollender ES, et al. Use of rifabutin with protease inhibitors for human immunodeficiency virus-infected patients with tuberculosis. Clin Infect Dis 2000; 30: 779-783.

166 Lopez-Cortes LF, Ruiz-Valderas R, Viciana $\mathrm{P}$, et al. Pharmacokinetic interactions between efavirenz and rifampicin in HIV-infected patients with tuberculosis. Clin Pharmacokinet 2002; 41: 681-690.

167 Soy D, Lopez E, Sarasa M, et al. Population pharmacokinetic modeling in HIV patients with tuberculosis treated with efavirenz and rifampicin. Abstract 15. 6th International
Workshop on Clinical Pharmacology of HIV Therapy, Quebec City, Canada, 2005.

168 Matteelli A, Regazzi M, Villani P, et al. Multiple-dose pharmacokinetics of efavirenz with and without the use of rifampicin in HIV-positive patients. Curr HIV Res 2007; 5 349-353.

169 Manosuthi W, Kiertiburanakul S, Sungkanuparph S, et al. Efavirenz $600 \mathrm{mg} \cdot$ day $^{-1}$ versus efavirenz $800 \mathrm{mg} \cdot$ day $^{-1}$ in HIVinfected patients with tuberculosis receiving rifampicin: 48 weeks results. AIDS 2006; 20: 131-132.

170 Pedral-Sampaio DB, Alves CR, Netto EM, et al. Efficacy and safety of efavirenz in HIV patients on rifampin for tuberculosis. Braz J Infect Dis 2004; 8: 211-216.

171 Orrell C, Cohen $\mathrm{K}$, Ive $\mathrm{P}$, et al. O124 efavirenz and rifampicin in the South African context: is there a need to dose increase efavirenz with concurrent rifampicin therapy? J Int AIDS Soc 2008; 11: Suppl. 1, O9.

172 Boulle A, Van Cutsem G, Cohen K, et al. Outcomes of nevirapine- and efavirenz-based antiretroviral therapy when coadministered with rifampicin-based antitubercular therapy. JAMA 2008; 300: 530-539.

173 Manosuthi W, Sungkanuparph S, Tantanathip P, et al. Body weight cutoff for daily dosage of efavirenz and 60-week efficacy of efavirenz-based regimen in human immunodeficiency virus and tuberculosis coinfected patients receiving rifampin. Antimicrob Agents Chemother 2009; 53: 4545-4548.

174 Friedland G, Khoo S, Jack C, et al. Administration of efavirenz $\left(600 \mathrm{mg} \cdot\right.$ day $\left.^{-1}\right)$ with rifampicin results in highly variable levels but excellent clinical outcomes in patients treated for tuberculosis and HIV. J Antimicrob Chemother 2006; 58: 1299-1302.

175 Schouten JT, Krambrink A, Ribaudo HJ, et al. Substitution of nevirapine because of efavirenz toxicity in AIDS clinical trials group A5095. Clin Infect Dis 2010; 50: 787-791.

176 Ribaudo HJ, Haas DW, Tierney C, et al. Pharmacogenetics of plasma efavirenz exposure after treatment discontinuation: an Adult AIDS Clinical Trials Group Study. Clin Infect Dis 2006; 42: 401-407.

177 Brennan-Benson P, Lyus R, Harrison T, et al. Pharmacokinetic interactions between efavirenz and rifampicin in the treatment of HIV and tuberculosis: one size does not fit all. AIDS 2005; 19: 1541-1543.

178 Cohen K, Meintjes G. Management of individuals requiring antiretroviral therapy and TB treatment. Curr Opin HIV AIDS 2010; 5: 61-69.

179 Oliva J, Moreno S, Sanz J, et al. Co-administration of rifampin and nevirapine in HIV-infected patients with tuberculosis. AIDS 2003; 17: 637-638.

180 Ribera E, Pou L, Lopez RM, et al. Pharmacokinetic interaction between nevirapine and rifampicin in HIV-infected patients with tuberculosis. J Acquir Immune Defic Syndr 2001; 28: $450-453$.

181 Robinson P, Lamson M, Gigliotti M, et al. Pharmacokinetic interaction between nevirapine and rifampicin. Abstract 60623 12th World AIDS conference, Geneva, Switzerland, 1998.

182 Autar RS, Wit FW, Sankote J, et al. Nevirapine plasma concentrations and concomitant use of rifampin in patients coinfected with HIV-1 and tuberculosis. Antivir Ther 2005; 10: 937-943.

183 Cohen K, van Cutsem G, Boulle A, et al. Effect of rifampicinbased antitubercular therapy on nevirapine plasma concentrations in South African adults with HIV-associated tuberculosis. J Antimicrob Chemother 2008; 61: 389-393.

184 Avihingsanon A, Manosuthi W, Kantipong $\mathrm{P}$, et al. Pharmacokinetics and 48-week efficacy of nevirapine: $400 \mathrm{mg}$ versus $600 \mathrm{mg}$ per day in HIV-tuberculosis coinfection receiving rifampicin. Antivir Ther 2008; 13: 529-536. 
185 Van Cutsem G, Cohen K, Bedelu M. TB/HIV co-infected patients on rifampicin containing treatment have equivalent ART treatment outcomes, and concurrent use of nevirapine is not associated with increase in hepatotoxicity. Abstract WePp0303. 3rd Conference on HIV Pathogenesis and Treatment, Rio de Janeiro, Brazil, 2005.

186 Van Heeswijk R, Hoetelmans R, Kestens D, et al. The effects of CYP3A4 modulation on the pharmacokinetics of TMC278, an investigational non-nucleoside reverse transcriptase inhibitor (NNRTI). Abstract 74. 7th International Workshop on Clinical Pharmacology of HIV Therapy Lisbon, Portugal, 2006.

187 La Porte CJ, Colbers EP, Bertz R, et al. Pharmacokinetics of adjusteddose lopinavir-ritonavir combined with rifampin in healthy volunteers. Antimicrob Agents Chemother 2004; 48: 1553-1560.

188 Nijland HM, L'Homme RF, Rongen GA, et al. High incidence of adverse events in healthy volunteers receiving rifampicin and adjusted doses of lopinavir/ritonavir tablets. AIDS 2008; 22: 931-935.

189 Veldkamp AI, Hoetelmans RM, Beijnen JH, et al. Ritonavir enables combined therapy with rifampin and saquinavir. Clin Infect Dis 1999; 29: 1586.

190 Ribera E, Azuaje C, Lopez RM, et al. Once-daily regimen of saquinavir, ritonavir, didanosine, and lamivudine in HIVinfected patients with standard tuberculosis therapy (TBQD Study). J Acquir Immune Defic Syndr 2005; 40: 317-323.

191 Ribera E, Azuaje C, Lopez RM, et al. Pharmacokinetic interaction between rifampicin and the once-daily combination of saquinavir and low-dose ritonavir in HIV-infected patients with tuberculosis. J Antimicrob Chemother 2007; 59: 690-697.

192 Schmitt C, Riek M, Winters K, et al. Unexpected hepatotoxicity of rifampin and saquinavir/ritonavir in healthy male volunteers. Arch Drug Inf 2009; 2: 8-16.

193 Acosta EP, Kendall MA, Gerber JG, et al. Effect of concomitantly administered rifampin on the pharmacokinetics and safety of atazanavir administered twice daily. Antimicrob Agents Chemother 2007; 51: 3104-3110.

194 Burger DM, Agarwala S, Child M, et al. Effect of rifampin on steady-state pharmacokinetics of atazanavir with ritonavir in healthy volunteers. Antimicrob Agents Chemother 2006; 50: 3336-3342.

195 Mallolas I, Sarasa M, Nomdedeu M, et al. Pharmacokinetic interaction between rifampicin and ritonavir-boosted atazanavir in HIV-infected patients. HIV Med 2007; 8: 131-134.

196 Boehringer Ingelheim Pharmaceuticals Inc. AptivusR package insert. 2005

197 Boulanger C, Hollender E, Farrell K, et al. Pharmacokinetic evaluation of rifabutin in combination with lopinavir-ritonavir in patients with HIV infection and active tuberculosis. Clin Infect Dis 2009; 49: 1305-1311.

198 L'Homme R F, Nijland HM, Gras L, et al. Clinical experience with the combined use of lopinavir/ritonavir and rifampicin. AIDS 2009; 23: 863-865.

199 DART Virology Trial Team. Virological response to a triple nucleoside/nucleotide analogue regimen over 48 weeks in HIV-1-infected adults in Africa. AIDS 2006; 20: 1391-1399.

200 Virological response to a triple nucleoside/nucleotide analogue regimen over 48 weeks in HIV-1-infected adults in Africa. AIDS 2006; 20: 1391-1399.

201 Srikantiah P, Walusimbi MN, Kayanja HK, et al. Early virological response of zidovudine/lamivudine/abacavir for patients coinfected with HIV and tuberculosis in Uganda. AIDS 2007; 21: 1972-1974.

202 Gulick RM, Ribaudo HJ, Shikuma CM, et al. Triple-nucleoside regimens versus efavirenz-containing regimens for the initial treatment of HIV-1 infection. N Engl J Med 2004; 350: 1850-1861.
203 Armstrong-James D, Menon-Johansson A, Pozniak A. The utility of nucleos(t)ide-only regimens in the treatment of Mycobacterium tuberculosis-HIV-1 coinfection. AIDS 2009; 23: 865-867.

204 Wenning LA, Hanley WD, Brainard DM, et al. Effect of rifampin, a potent inducer of drug-metabolizing enzymes, on the pharmacokinetics of raltegravir. Antimicrob Agents Chemother 2009; 53: 2852-2856.

205 Abel S, Jenkins TM, Whitlock LA, et al. Effects of CYP3A4 inducers with and without CYP3A4 inhibitors on the pharmacokinetics of maraviroc in healthy volunteers. Br J Clin Pharmacol 2008; 65: Suppl. 1, 38-46.

206 Patel IH, Zhang X, Nieforth K, et al. Pharmacokinetics, pharmacodynamics and drug interaction potential of enfuvirtide. Clin Pharmacokinet 2005; 44: 175-186.

207 Jindani A, Nunn AJ, Enarson DA. Two 8-month regimens of chemotherapy for treatment of newly diagnosed pulmonary tuberculosis: international multicentre randomised trial. Lancet 2004; 364: 1244-1251.

208 Okwera A, Whalen C, Byekwaso F, et al. Randomised trial of thiacetazone and rifampicin-containing regimens for pulmonary tuberculosis in HIV-infected Ugandans. The Makerere University-Case Western University Research Collaboration. Lancet 1994; 344: 1323-1328.

209 Coyne KM, Pozniak AL, Lamorde M, et al. Pharmacology of second-line antituberculosis drugs and potential for interactions with antiretroviral agents. AIDS 2009; 23: 437-446.

210 Yee D, Valiquette C, Pelletier M, et al. Incidence of serious side effects from first-line antituberculosis drugs among patients treated for active tuberculosis. Am J Respir Crit Care Med 2003; 167: 1472-1477.

211 Devoto FM, Gonzalez C, Iannantuono R, et al. Risk factors for hepatotoxicity induced by antituberculosis drugs. Acta Physiol Pharmacol Ther Latinoam 1997; 47: 197-202.

212 Dean GL, Edwards SG, Ives NJ, et al. Treatment of tuberculosis in HIV-infected persons in the era of highly active antiretroviral therapy. AIDS 2002; 16: 75-83.

213 Breen RA, Miller RF, Gorsuch T, et al. Adverse events and treatment interruption in tuberculosis patients with and without HIV co-infection. Thorax 2006; 61: 791-794.

214 Breen RA, Lipman MC, Johnson MA. Increased incidence of peripheral neuropathy with co-administration of stavudine and isoniazid in HIV-infected individuals. AIDS 2000; 14: 615.

215 Westreich DJ, Sanne I, Maskew M, et al. Tuberculosis treatment and risk of stavudine substitution in first-line antiretroviral therapy. Clin Infect Dis 2009; 48: 1617-1623.

216 Kura MM, Hira SK. Reintroducing antituberculosis therapy after Stevens-Johnson syndrome in human immunodeficiency virusinfected patients with tuberculosis: role of desensitization. Int Dermatol 2001; 40: 481-484.

217 Galloe AM, Graudal N, Christensen HR, et al. Aminoglycosides: single or multiple daily dosing? A meta-analysis on efficacy and safety. Eur J Clin Pharmacol 1995; 48: 39-43.

218 Labarga P, Barreiro P, Martin-Carbonero L, et al. Kidney tubular abnormalities in the absence of impaired glomerular function in HIV patients treated with tenofovir. AIDS 2009; 23: 689-696.

219 Blanc FX, Havlir DV, Onyebujoh PC, et al. Treatment strategies for HIV-infected patients with tuberculosis: ongoing and planned clinical trials. J Infect Dis 2007; 196: Suppl. 1, S46-S51.

220 Churchyard GJ, Kleinschmidt I, Corbett EL, et al. Factors associated with an increased case-fatality rate in HIV-infected and non-infected South African gold miners with pulmonary tuberculosis. Int J Tuberc Lung Dis 2000; 4: 705-712.

221 Abdool Karim SS, Naidoo K, Grobler A, et al. Timing of initiation of antiretroviral drugs during tuberculosis therapy. N Engl J Med 2010; 362: 697-706. 
222 Lawn SD, Myer L, Bekker LG, et al. Tuberculosis-associated immune reconstitution disease: incidence, risk factors and impact in an antiretroviral treatment service in South Africa. AIDS 2007; 21: 335-341.

223 Blanc FX, Sok T, Laureillard D, et al. Significant enhancement in survival with early (2 weeks) vs. late (8 weeks) initiation of highly active antiretroviral treatment (HAART) in severely immunosuppressed HIV-infected adults with newly diagnosed tuberculosis. Abstract THLBB106. 18th International AIDS Conference, Vienna, Austria, 2010.

224 Torok M, Yen N, Chau $\mathrm{T}$, et al. Randomised controlled trial of immediated versus deferred antiretroviral therapy in HIV-associated tuberculosis meningitis. Abstract H-1224. 49th Interscience Conference on Antimicrobial Agents and Chemotherapy, San Francisco, United States of America, 2009.

225 Burman WJ, Jones BE. Treatment of HIV-related tuberculosis in the era of effective antiretroviral therapy. Am J Respir Crit Care Med 2001; 164: 7-12.

226 Blumberg HM, Burman WJ, Chaisson RE, et al. American Thoracic Society/Centers for Disease Control and Prevention/ Infectious Diseases Society of America: treatment of tuberculosis. Am J Respir Crit Care Med 2003; 167: 603-662.

227 Moreno S. Antiviral therapy and tuberculosis, Abstract TuOr171. 14th World AIDS Conference, Barcelona, Spain, 2002.

228 Navas E, Oliva J, Miralles P. Antiretroviral therapy in AIDS patient. Abstract ThPeB7271. 14th World AIDS Conference, Barcelona, Spain, 2002.

229 French MA, Price P, Stone SF. Immune restoration disease after antiretroviral therapy. AIDS 2004; 18: 1615-1627.

230 Marais S, Wilkinson RJ, Pepper DJ, et al. Management of patients with the immune reconstitution inflammatory syndrome. Curr HIV/AIDS Rep 2009; 6: 162-171.

231 Meintjes G, Lawn SD, Scano F, et al. Tuberculosis-associated immune reconstitution inflammatory syndrome: case definitions for use in resource-limited settings. Lancet Infect Dis 2008; 8: 516-523.

232 Narita M, Ashkin D, Hollender ES, et al. Paradoxical worsening of tuberculosis following antiretroviral therapy in patients with AIDS. Am J Respir Crit Care Med 1998; 158: 157-161.

233 Breen RA, Smith CJ, Bettinson $\mathrm{H}$, et al. Paradoxical reactions during tuberculosis treatment in patients with and without HIV co-infection. Thorax 2004; 59: 704-707.

234 Breton G, Duval X, Estellat C, et al. Determinants of immune reconstitution inflammatory syndrome in HIV type 1-infected patients with tuberculosis after initiation of antiretroviral therapy. Clin Infect Dis 2004; 39: 1709-1712.

235 Manosuthi W, Kiertiburanakul S, Phoorisri T, et al. Immune reconstitution inflammatory syndrome of tuberculosis among HIV-infected patients receiving antituberculous and antiretroviral therapy. J Infect 2006; 53: 357-363.

236 Meintjes G, Rangaka MX, Maartens G, et al. Novel relationship between tuberculosis immune reconstitution inflammatory syndrome and antitubercular drug resistance. Clin Infect Dis 2009; 48: 667-676.

237 Manosuthi W, Van Tieu H, Mankatitham W, et al. Clinical case definition and manifestations of paradoxical tuberculosis-associated immune reconstitution inflammatory syndrome. AIDS 2009; 23: 2467-2471.

238 Pepper DJ, Marais S, Maartens G, et al. Neurologic manifestations of paradoxical tuberculosis-associated immune reconstitution inflammatory syndrome: a case series. Clin Infect Dis 2009; 48: e96-e107.

239 Shelburne SA, Visnegarwala F, Darcourt J, et al. Incidence and risk factors for immune reconstitution inflammatory syndrome during highly active antiretroviral therapy. AIDS 2005; 19 : 399-406.

240 Michailidis C, Pozniak AL, Mandalia S, et al. Clinical characteristics of IRIS syndrome in patients with HIV and tuberculosis. Antivir Ther 2005; 10: 417-422.

241 Burman W, Weis S, Vernon A, et al. Frequency, severity and duration of immune reconstitution events in HIV-related tuberculosis. Int J Tuberc Lung Dis 2007; 11: 1282-1289.

242 Haddow LJ, Moosa MY, Easterbrook PJ. Validation of a published case definition for tuberculosis-associated immune reconstitution inflammatory syndrome. AIDS, 24 103-108.

243 Meintjes G, Wilkinson RJ, Morroni C, et al. Randomized placebocontrolled trial of prednisone for paradoxical tuberculosisassociated immune reconstruction inflammatory syndrome. AIDS 2010; 24: 2381-2390.

244 Elliott AM, Halwiindi B, Bagshawe A, et al. Use of prednisolone in the treatment of HIV-positive tuberculosis patients. Q J Med 1992; 85: 855-860.

245 Volkow PF, Cornejo P, Zinser JW, et al. Life-threatening exacerbation of Kaposi's sarcoma after prednisone treatment for immune reconstitution inflammatory syndrome. AIDS 2008; 22: 663-665.

246 Moh R, Danel C, Messou E, et al. Incidence and determinants of mortality and morbidity following early antiretroviral therapy initiation in HIV-infected adults in West Africa. AIDS 2007; 21 2483-2491.

247 Brinkhof MW, Egger M, Boulle A, et al. Tuberculosis after initiation of antiretroviral therapy in low-income and highincome countries. Clin Infect Dis 2007; 45: 1518-1521.

248 Lawn SD, Wilkinson RJ, Lipman MC, et al. Immune reconstitution and "unmasking" of tuberculosis during antiretroviral therapy. Am J Respir Crit Care Med 2008; 177: 680-685

249 Lawn SD, Wainwright H, Orrell C. Fatal unmasking tuberculosis immune reconstitution disease with bronchiolitis obliterans organizing pneumonia: the role of macrophages. AIDS 2009; 23: $143-145$

250 Goldsack NR, Allen S, Lipman MC. Adult respiratory distress syndrome as a severe immune reconstitution disease following the commencement of highly active antiretroviral therapy. Sex Transm Infect 2003; 79: 337-338.

251 Crump JA, Tyrer MJ, Lloyd-Owen SJ, et al. Miliary tuberculosis with paradoxical expansion of intracranial tuberculomas complicating human immunodeficiency virus infection in a patient receiving highly active antiretroviral therapy. Clin Infect Dis 1998; 26: 1008-1009.

252 Tahir M, Sinha S, Sharma SK, et al. Immune reconstitution inflammatory syndrome manifesting as disseminated tuberculosis, deep venous thrombosis, encephalopathy and myelopathy. Indian J Chest Dis Allied Sci 2008; 50: 363-364.

253 Chen WL, Lin YF, Tsai WC, et al. Unveiling tuberculous pyomyositis: an emerging role of immune reconstitution inflammatory syndrome. Am J Emerg Med 2009; 27: e251-e252.

254 Koenig SP, Riviere C, Leger P, et al. High mortality among patients with AIDS who received a diagnosis of tuberculosis in the first 3 months of antiretroviral therapy. Clin Infect Dis 2009; 48: 829-831.

255 Akolo C, Adetifa I, Shepperd S, et al. Treatment of latent tuberculosis infection in HIV infected persons. Cochrane Database Syst Rev 2010; 1: CD000171.

256 Elzi L, Schlegel M, Weber R, et al. Reducing tuberculosis incidence by tuberculin skin testing, preventive treatment, and antiretroviral therapy in an area of low tuberculosis transmission. Clin Infect Dis 2007; 44: 94-102. 
257 Kranzer K, Houben RM, Glynn JR, et al. Yield of HIV-associated tuberculosis during intensified case finding in resource-limited settings: a systematic review and meta-analysis. Lancet Infect Dis 2010; 10: 93-102.

258 Comstock GW, Baum C, Snider DE Jr. Isoniazid prophylaxis among Alaskan Eskimos: a final report of the bethel isoniazid studies. Am Rev Respir Dis 1979; 119: 827-830.

259 Johnson JL, Okwera A, Hom DL, et al. Duration of efficacy of treatment of latent tuberculosis infection in HIV-infected adults. AIDS 2001; 15: 2137-2147.
260 Quigley MA, Mwinga A, Hosp M, et al. Long-term effect of preventive therapy for tuberculosis in a cohort of HIV-infected Zambian adults. AIDS 2001; 15: 215-222.

261 Mwinga A, Hosp M, Godfrey-Faussett P, et al. Twice weekly tuberculosis preventive therapy in HIV infection in Zambia. AIDS 1998; 12: 2447-2457.

262 Samandari T. Randomized, placebo controlled trial of 6 vs 34 months of isoniazid TB preventative therapy for HIV-infected adults in Botswana. Paper \#104LB. 17th Conference on Retrovirusses and Opportunistic Infections. San Francisco, USA, 2009. 